\title{
Synaptic integration of subquantal neurotransmission by co-localized G protein coupled receptors in presynaptic terminals
}

Abbreviated Title: Presynaptic GPCR mediated synaptic integration

Emily Church ${ }^{1,3,4}$, Edaeni Hamid ${ }^{2,3,4}$, Zack Zurawski ${ }^{1}$, Mariana Potcoava ${ }^{1}$, Eden Flores-Barrera ${ }^{1}$, Adriana Caballero ${ }^{1}$, Kuei Y. Tseng ${ }^{1}$ and Simon Alford ${ }^{1 *}$

${ }^{1}$ Department of Anatomy and Cell Biology, University of Illinois at Chicago, 808 S Wood Street, Chicago IL 60612

${ }^{2}$ Department of Biological Sciences, University of Illinois at Chicago, 840 West Taylor Street, Chicago IL 60607

${ }^{3}$ Graduate Program in Neuroscience, University of Illinois at Chicago, 840 S Wood St, Chicago IL 60612

${ }^{4}$ These authors contributed equally to this work.

${ }^{*}$ Corresponding Author Email: $\underline{\text { sta@uic.edu }}$

Number of pages: 65

Number of figures: 11

Number of tables: 1

Number of Multimedia items: 2

Number of words in Abstract: 250

Number of words in Introduction: 650

Number of words in Discussion: 1498

Conflict of Interest: none

Acknowledgements: We would like to thank Drs Heidi Hamm, Janet Richmond and Jonathon Art for helpful discussions throughout the course of this study and of this manuscript. This work was funded by NIH grants R01 MH084874 and R01 NS052699 to SA, R01 MH086507 to KYT, and F31 NS063662 to EH.

\section{Abstract}

In presynaptic terminals membrane-delimited $\mathrm{G}_{\mathrm{i} / 0}$-mediated presynaptic inhibition is ubiquitous 
and acts through G $\beta \gamma$ to inhibit $\mathrm{Ca}^{2+}$ entry, or directly at SNARE complexes to inhibit $\mathrm{Ca}^{2+}$ dependent synaptotagmin-SNARE complex interactions. At CA1-subicular presynaptic terminals $5-\mathrm{HT}_{1 \mathrm{~B}}$ and $\mathrm{GABA}_{\mathrm{B}}$ receptors colocalize. $\mathrm{GABA}_{\mathrm{B}}$ receptors inhibit $\mathrm{Ca}^{2+}$ entry, whereas $5-\mathrm{HT}_{1 \mathrm{~B}}$ receptors target SNARE complexes. We demonstrate in male and female rats that $\mathrm{GABA}_{\mathrm{B}}$ receptors receptors alter $\mathrm{P}_{\mathrm{r}}$, whereas $5-\mathrm{HT}_{1 \mathrm{~B}}$ receptors reduce evoked cleft glutamate concentrations allowing differential inhibition of AMPA and NMDA receptor EPSCs. This reduction in cleft glutamate concentration was confirmed by imaging glutamate release using a genetic sensor (iGluSnFR).Simulations of glutamate release and postsynaptic glutamate receptor currents were made. We tested effects of changes in vesicle numbers undergoing fusion at single synapses, relative placement of fusing vesicles and postsynaptic receptors, and the rate of release of glutamate from a fusion pore. Experimental effects of $P_{r}$ changes, consistent with $\mathrm{GABA}_{\mathrm{B}}$ receptor effects, were straightforwardly represented by changes in numbers of synapses. The effects of $5-\mathrm{HT}_{1 \mathrm{~B}}$ receptor-mediated inhibition are well-fit by simulated modulation of the release rate of glutamate into the cleft. Colocalization of different actions of GPCRs provide synaptic integration within presynaptic terminals. Train-dependent presynaptic $\mathrm{Ca}^{2+}$ accumulation forces frequency-dependent recovery of neurotransmission during $5-\mathrm{HT}_{1 \mathrm{~B}}$ receptor activation. This is consistent with competition between $\mathrm{Ca}^{2+}$ synaptotagmin and $\mathrm{G} \beta \gamma$ at SNARE complexes. Thus, stimulus trains in 5- $\mathrm{HT}_{1 \mathrm{~B}}$ receptor agonist unveil dynamic synaptic modulation and a sophisticated hippocampal output filter that itself is modulated by colocalized $\mathrm{GABA}_{\mathrm{B}}$ receptors which alter presynaptic $\mathrm{Ca}^{2+}$. In combination these pathways allow complex presynaptic integration. 


\section{Significance Statement}

Two G protein coupled receptors colocalize at presynaptic sites, to mediate presynaptic modulation by

$\mathrm{G} \beta \gamma$, but one - $\mathrm{a} G A B A_{B}$ receptor inhibits $\mathrm{Ca}^{2+}$ entry while another - a 5- $\mathrm{HT}_{1 \mathrm{~B}}$ receptor competes with $\mathrm{Ca}^{2+}$-synaptotagmin binding to the synaptic vesicle machinery. We have investigated downstream effects of signaling and integrative properties of these receptors. Their effects are profoundly different. GABA $A_{B}$ receptors alter $\mathrm{P}_{\mathrm{r}}$ leaving synaptic properties unchanged, while $5-\mathrm{HT}_{1 \mathrm{~B}}$ receptors fundamentally change properties of synaptic transmission, modifying AMPA receptor but sparing NMDA receptor responses. Coactivation of these receptors allows synaptic integration because of convergence of $\mathrm{GABA}_{B}$ receptor alteration on $\mathrm{Ca}^{2+}$ and the effect of this altered $\mathrm{Ca}^{2+}$ signal on $5-\mathrm{HT}_{1 \mathrm{~B}}$ receptor signaling. This presynaptic convergence provides a novel form of synaptic integration. 


\section{Introduction}

G protein-coupled receptors (GPCRs) control neurotransmitter release at all synapses via membrane delimited actions of $\mathrm{G} \beta \gamma$ (Betke et al., 2012). Much attention has been placed on $\mathrm{G}_{\mathrm{i} / \mathrm{o}}$ G protein modulation of $\mathrm{Ca}^{2+}$ entry (Tedford and Zamponi, 2006). This alters synaptic vesicle fusion probability $\left(\mathrm{P}_{\mathrm{r}}\right)($ Hessler et al., 1993); a phenomenon taken as proof of presynaptic action (Dobrunz and Stevens, 1997). However, at least one other membrane delimited action of G $\beta \gamma$ occurs. At synapses in lamprey, in amygdala, hippocampus, and in chromaffin and PC12 cells, GPCRs modulate exocytosis via G $\beta \gamma$-SNARE complex interactions (Blackmer et al., 2001;

Takahashi et al., 2001; Blackmer et al., 2005; Chen et al., 2005). This modulation is caused by G $\beta \gamma$ competition with synaptotagmin for binding to c-terminal SNAP-25 on SNARE complexes of primed vesicles. Mutation of this SNAP-25/G $\beta \gamma$ interaction site in a mouse model demonstrates central effects on anxiety, spatial memory, and motor control, as well as endocrine release and metabolism implying broad implications for this form of exocytotic modulation in the brain and the periphery (Zurawski et al., 2019). The mechanistic effects of these different modulatory processes on synaptic transmission remain debated (Pawlu et al., 2004; Balaji and Ryan, 2007; Alabi and Tsien, 2013).

That G $\beta \gamma$ directly interacts directly with the SNARE complex opens new possibilities for the mechanistic effect of its signaling at presynaptic terminals. If G $\beta \gamma$ interacts with a subset of primed vesicles at the terminal it might alter $\mathrm{P}_{\mathrm{r}}$ at just those sites or it might change the mode of vesicle fusion (Elhamdani et al., 2006; Alabi and Tsien, 2013). If the synapse releases just one vesicle - if it is univesicular (Maschi and Klyachko, 2020) - altering $P_{r}$ changes the number of synaptic sites releasing transmitter for any given action potential. This will not alter transmitter concentration at each site. In contrast, variation in synaptic cleft neurotransmitter concentration might be caused by alterations in $\mathrm{P}_{\mathrm{r}}$ within multivesicular release synapses (Rudolph et al., 2015). Concentrations of transmitter at postsynaptic receptors might also be changed by 
altering the location of release sites within active zones with respect to the postsynaptic receptors (Tang et al., 2016). Finally, a change in synaptic cleft transmitter concentration may follow changes in vesicle fusion (Gandhi and Stevens, 2003). In the latter case, vesicle fusion begins with pore formation (Spruce et al., 1990), which may expand to collapse the vesicle into the plasmalemma. The c-terminus of the SNARE complex protein, SNAP-25 is required for this

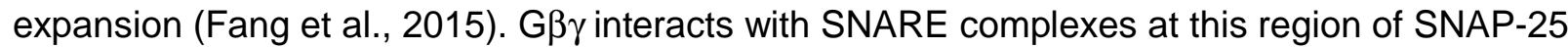
to compete with $\mathrm{Ca}^{2+}$-synaptotagmin interaction during evoked fusion (Zurawski et al., 2017). Thus, G $\beta \gamma$-SNARE interaction opens the possibility that GPCRs regulate the synaptic vesicle fusion mode and cleft neurotransmitter concentrations.

These contrasting mechanisms provide a mechanism of presynaptic receptor-mediated synaptic integration. We have previously demonstrated that colocalized but different $\mathrm{G}_{\mathrm{i} / \mathrm{o}}$ GPCRs coupled receptors target $\mathrm{G} \beta \gamma$ to different effector systems. In particular at CA1-subicular synapses we show $\mathrm{GABA}$ receptors reduce $\mathrm{Ca}^{2+}$ entry and $\mathrm{P}_{\mathrm{r}}$ whereas $5-\mathrm{HT}_{1 \mathrm{~B}}$ receptors modify cleft glutamate concentrations on single evoked vesicle fusion events to allow receptordependent modulation of postsynaptic receptors. Neither of these mechanisms alter action potential invasion of the recorded synapses as demonstrated by the reliability of action potential-evoked presynaptic $\mathrm{Ca}^{2+}$ transients (Hamid et al., 2014). Monte Carlo simulation of glutamate release at modeled synapses reproduces experimental results supporting the hypothesis that $\mathrm{GABA}_{\mathrm{B}}$ receptors alter $\mathrm{P}_{\mathrm{r}}$ at univesicular synapses whereas $5-\mathrm{HT}_{1 \mathrm{~B}}$ receptor action is best explained by slowing of glutamate release through a restricted fusion pore. This novel modulation provides finer tuning of synaptic transmission than changes in $\mathrm{P}_{\mathrm{r}}$ and creates a synaptic filter that selects for transmission of NMDA receptor-mediated events and trains of activity. $G A B A_{B}$ receptors, inhibit synaptic responses by changing $P_{r}$ regardless of frequency. However, because they modify presynaptic $\mathrm{Ca}^{2+}$ entry which alters $\mathrm{G} \beta \gamma$-competition with 
synaptotagmin at SNARE complexes, $\mathrm{GABA}_{\mathrm{B}}$ receptors cause meta-modulation by reshaping effects of $5-\mathrm{HT}_{1 \mathrm{~B}}$ receptors. Thus, presynaptic terminals show synaptic integration.

\section{Materials and Methods}

\section{The preparation}

Experiments were performed on hippocampal slices $(300 \mu \mathrm{m})$ of 21-22-day-old Sprague-Dawley rats anesthetized with isoflurane and decapitated in accordance with institutional guidelines. Hippocampi were isolated under semi-frozen Krebs Henseleit solution (in mM): $124 \mathrm{NaCl}, 26$ $\mathrm{NaHCO}_{3}, 1.25 \mathrm{NaH}_{2} \mathrm{PO}_{4}, 3 \mathrm{KCl}, 2 \mathrm{CaCl}_{2}, 1 \mathrm{MgCl}_{2}, 10 \mathrm{D}$-glucose, bubbled with $95 \% \mathrm{O}_{2}-5 \% \mathrm{CO}_{2}$ and sliced using a Vibratome (Leica VT1200, Leica Microsystems Inc, Buffalo Grove IL) except for experiments in which high $\mathrm{Ca}^{2+}$ concentrations were used. In these experiments to prevent calcium carbonate precipitation, bicarbonate buffer was substituted with HEPES using solution of the following composition in mM: $145 \mathrm{NaCl}, 5 \mathrm{HEPES}, 1.25 \mathrm{NaH}_{2} \mathrm{PO}_{4}, 3 \mathrm{KCl}, 2$ or $10 \mathrm{CaCl}_{2}, 1$ $\mathrm{MgCl}_{2}, 10$ D-glucose, adjusted to $\mathrm{pH} 7.4$ with $\mathrm{NaOH}$ and bubbled with $\mathrm{O}_{2}-100 \% \mathrm{CO}_{2}$. All recording were performed in a constant flow recording chamber in which the slice were held down with a harp. The recording chamber was superfused at approximately $2 \mathrm{ml} / \mathrm{min}$ and maintained at $28^{\circ} \mathrm{C}$.

\section{Electrophysiology}

Subicular pyramidal neurons were whole-cell clamped by visual identification using an upright microscope illuminated via a fibre optic source. Recording use an Axopatch 200A or B amplifier (Axon Instruments). Patch pipettes (4-5 M 2 ) contained solution (in $\mathrm{mM}$ ): cesium (for voltage clamp) or potassium methane sulfonate (for current clamp) $146, \mathrm{MgCl}_{2}$ 2, EGTA 5, HEPES 9.1, $\mathrm{pH}$ adjusted to 7.2 with $\mathrm{CsOH}$ or $\mathrm{KOH}$. Series resistance was monitored by applying a 5 to 10 $\mathrm{mV}$ voltage step before each evoked synaptic response. If any series resistance change 
recorded during the experiment exceeded $20 \%$, the cell was discarded from analysis. Focal stimuli (0.2 ms, $20 \mu \mathrm{A}$ or less) were applied over CA1 axons using glass insulated monopolar tungsten microelectrodes (Fig 1A) (Hamid et al., 2014). Immediately after obtaining whole cell access for up to 15 minutes, a hyperpolarization and reduction in impedance could be sometimes be recorded on baclofen application. Baclofen activates postsynaptic G protein activated inwardly rectifying $\mathrm{K}^{+}(\mathrm{GIRK})$ currents to cause a change in postsynaptic impedance. This was not seen following CP93129 application. Nevertheless, in all recordings, including during those with baclofen, postsynaptic input impedance was tested with current pulses throughout the entirety of the experiment (Fig. 4). However, the baclofen evoked reduction in impedance was lost after the initial 15 min period of recording. All experimental recordings of EPSCs were made after this initial period of recording and no effect of baclofen on neuron impedance was recorded during any voltage clamp experiments. Whole cell impedance correction was not used during the experiment to avoid changes causing uncontrolled alterations in apparent EPSC amplitudes over the long recording period.

\section{Expression of iGluSnFR in hippocampus}

An AAV5 containing the glutamate sensor iGluSnFr under a human synapsin promoter was intracerebrally injected in rats at postnatal days 21-22. pAAV.hSyn.iGluSnFr.WPRE.SV40 was a gift from Loren Looger (Addgene plasmid \# 98929). Briefly, rats were anesthetized with isoflurane during the stereotaxic surgery and a volume of $0.2 \mathrm{uL}$ of iGluSnFr was injected in the dorsal hippocampus at the following coordinates: A/P: $-4.0, \mathrm{M} / \mathrm{L}:+/-2.7$, and D/V: -1.8 . Hippocampal slices were prepared from these animals 7 and 14 days after the surgery using the same procedures as described for electrophysiological experiments.

\section{Imaging Experiments}


Line-scan confocal imaging as previously described (Hamid et al., 2019) was used for $\mathrm{Ca}^{2+}$ transient recording in presynaptic varicosities following single action potentials stimulated with somatic whole-cell electrodes. Alexa 594 hydrazide was excited at 568 nm. Fluo-5F was separately excited (488 $\mathrm{nm})$ and imaged in bandpass (510-560 nm). Images were taken separately to ensure no cross-channel bleed-through. This was confirmed with neurons filled with only one dye. No bleed-through image was discernible for either dye to the incorrect channel. Varicosities were identified 20-35 mins after whole cell access by imaging the Alexa 594 hydrazide dye and tracking the axon from the filled soma to its projection into the subiculum. $\mathrm{Ca}^{2+}$ transients at these varicosities were imaged in line scanning mode $(500 \mathrm{~Hz})$ for up to $1 \mathrm{~s}$ during stimuli to the soma to evoke action potentials. Image analysis was performed within ImageJ and images are represented as linear with the applied LUT mapping.

For Lattice Light Sheet Microscopy (LLSM) hippocampal slices were placed on cover slips previously coated with $50 \mathrm{mg} / \mathrm{ml} 300,000 \mathrm{MW}$ poly-lysine in a custom perfused recording chamber under the LLSM objective lenses (Fig.5A). The LLSM was custom designed in our laboratory to allow simultaneous electrophysiology, but based on a Janelia Farms design (Chen et al., 2014). A twisted pair Nichrome stimulating electrode was positioned at the same location

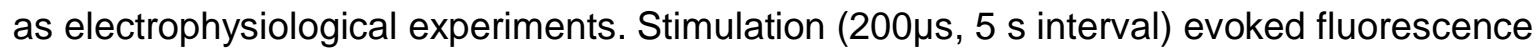
transients stochastically across the $51 \times 51 \mu \mathrm{m}$ field of view. We imaged transients using LLSM at frame rates of up to $80 \mathrm{~Hz}$ in single planes across multiple hotspots in a single axon. Transients were imaged in sequential LLSM frames at the same z position.

\section{Experimental Design and Statistical Analyses}

For all values of EPSC amplitude or fits to the EPSC rise and decays, the mean was taken of at least 10 evoked traces of EPSCs for each condition for each recorded neuron. Student paired two-tailed t-tests were used to calculate the significance of simple paired data sets. Comparison 
of multiple data sets under similar conditions were made using one way ANOVA, and if necessary followed with a Post Hoc Tukey HSD test for significance of each manipulation against all others. Results are presented as numbers of recordings $(n)$, the values of the means \pm standard error of the mean, and for each statistical analysis are presented as degrees of freedom, F or t statistic, degrees of freedom, and absolute value of probability (p). Post Hoc tests following significance obtained from an ANOVA give maximum values of $p$ from tables. All values of $p$ were from two-tailed tests. All replicates are from different neuronal recordings in different hippocampal slices. Significance is indicated in figures over box plots and histograms as follow: ${ }^{*} p<0.05,{ }^{* *} p<0.01,{ }^{* *} p<0.001$.

\section{Monte Carlo simulations.}

Monte Carlo simulations were applied to neurotransmitter release through an expanding model of a synaptic vesicle fusion pore within a simulated synapse. Simulations were run in the MCell environment (Kerr et al., 2008) in which a simple 3D mesh model of a synaptic cleft was created. The cleft was modeled as disc with a $300 \mathrm{~nm}$ diameter and a thickness of $20 \mathrm{~nm}$. Neurotransmitter release was modeled from from 1 to 3 vesicles with internal diameters of 25 $\mathrm{nm}$ fusing with expanding pores growing from $0.4 \mathrm{~nm}$ to complete opening to the diameter of the vesicle over a period varying from $200 \mu$ s to over $20 \mathrm{~ms}$. An example of the sequence of frames for a single pore and its expansion and loss of glutamate to the synaptic cleft is shown in Multimedia file 1. Glutamate escape from the simulated synaptic cleft was slowed by limiting the thickness of the cleft at its edges. This was varied systematically to result in a glutamate decay to $10 \%$ of peak in $1 \mathrm{~ms}$ (Clements et al., 1992; Asztely et al., 1997) following the release of 5000 glutamate molecules. After escape from the cleft, glutamate moleculas were removed from the model by simulating pumps external to the synaptic cleft. The vesicles were modeled containing from 700 to 20000 glutamate molecules. Kinetic models of glutamate receptors were placed in the postsynaptic disc (20 NMDA and 20 AMPA receptors) enabling simulation of the 
binding, activation, desensitation, inactivation and unbinding of these receptors. Kinetic models of the receptors are shown in Figure 6. Model parameters including those of the receptor kinetic models used are included in table 1. Animations of these simulations are shown in Multimedia files 1 and 2.

Imaging

Two imaging forms were used. Line scan confocal imaging revealed individual presynaptic action potential-evoked Ca2+ transients.

\section{Code Accessibility}

Simulation parameter files are available at: https://alford.lab.uic.edu/GPCRs.html and at ModelDB for requested access at http://modeldb.yale.edu/266839 prior to publication of this work. This will be made public on publication.

The authors declare that experimental data supporting the findings of this study are available within the paper.

\section{Results}

\section{$G A B A_{B}$ and $5-H T_{1 B}$ receptors inhibit synaptic transmission from CA1 to subiculum}

5- $\mathrm{HT}_{1 \mathrm{~B}}$ and $\mathrm{GABA}$ receptors have previously been shown to be co-expressed in $\mathrm{CA} 1$ axon presynaptic terminals. (Boeijinga and Boddeke, 1996; Bonaventure et al., 1998; Lein et al., 2007; Hamid et al., 2014) where both receptors inhibit synaptic transmission, but by different mechanisms. We have previously shown that $\mathrm{GABA}_{\mathrm{B}}$ receptors inhibit $\mathrm{Ca}^{2+}$ entry, while $5-\mathrm{HT}_{1 \mathrm{~B}}$ receptors cause Gß $\gamma$ to act directly at the SNARE complex (Hamid et al., 2014). The amount of inhibition of $\mathrm{Ca}^{2+}$ entry by $\mathrm{GABA}_{\mathrm{B}}$ receptors in that study was sufficient to account for the effect of baclofen on synaptic transmission. In contrast, the effect of CP93129 was eliminated by treatment of the tissue with Botulinum A toxin to remove the c-terminal 9 residues from SNAP25 and in a further study (Zurawski et al., 2019) genetic manipulation of the c-terminal of SNAP- 
25 also prevented $5-\mathrm{HT}_{1 \mathrm{~B}}$ receptor modulation of neurotransmitter release. We also showed in those studies no loss of transmission between soma and axons. This was indicated by $\mathrm{Ca}^{2+}$ transients, that were unnaffected by $5-\mathrm{HT}_{1 \mathrm{~B}}$ receptors and reduced in amplitude, but not prevented by $\mathrm{GABA}_{B}$ receptors (Hamid et al., 2014).

To investigate their effects on neurotransmitter release, we whole cell voltage clamped subicular pyramidal neurons (Fig. 1A) and stimulated CA1 axons with glass coated tungsten microelectrodes at low intensity to ensure focal stimulation (5-20 $\mu \mathrm{A}, 200 \mu \mathrm{s})$. Recorded events were of low amplitude (Fig 1B): approximately 10 times the unitary amplitude determined from spontaneous release in TTX shown in earlier work (Hamid et al., 2014), which ensured that responses were monosynaptic. To prevent polysynaptic firing by recurrent excitation of CA1 neurons, the tissue was cut at the CA1-subicular boundary. We recorded responses in bicuculline $(5 \mu \mathrm{M})$ and 2-amino-5-phosphonopentanoic acid (AP5, $50 \mu \mathrm{M})$ to isolate responses to AMPA receptor-mediated currents and record control responses. We applied the selective 5$\mathrm{HT}_{1 \mathrm{~B}}$ receptor agonist CP93129. Effects of a saturating concentration $(1 \mu \mathrm{M})$ and at approximately the EC50 (50 nM) is shown (Fig. 1Ba, Fig. 1Da for the concentration response). CP93129 reduced the EPSC peak amplitude to $19.6 \pm 3.9 \%$ at a saturating dose $(1 \mu \mathrm{M}, \mathrm{n}=8$; $E C 50=0.033 \pm 0.04 \mu \mathrm{M})$. These EPSCs are also inhibited by the $\mathrm{GABA}_{\mathrm{B}}$ receptor agonist, baclofen to $7.2 \pm 2.3 \%$ of control $(100 \mu \mathrm{M}$ baclofen, $\mathrm{n}=5$, EC50=0.35 $\pm 0.18 \mu \mathrm{M})$ (Fig. 1Bb, Db).

We have previously shown that $5-\mathrm{HT}_{1 \mathrm{~B}}$ receptors target $\mathrm{G} \beta \gamma$ to SNARE complexes in $\mathrm{CA} 1$ terminals (Hamid et al., 2014), and G $\beta \gamma$ competes with $\mathrm{Ca}^{2+}$-synaptotagmin binding to SNARE complexes. In lamprey this may confer $\mathrm{Ca}^{2+}$ dependency on inhibition (Yoon et al., 2007). To test for this in CA1 subicular synapses, we recorded EPSCs in HEPES buffered Ringer (to prevent $\mathrm{Ca}^{2+}$ precipitation). Increasing $\mathrm{CaCl}_{2}$ concentrations $(10 \mathrm{mM})$ enhanced the EPSC (Fig. 1Ca,b), but CP93129 now caused significantly less inhibition (Fig. 1Cb, Da; at 50nM, paired Students t test, $\mathrm{t}(15)=6.00, \mathrm{p}=0.00001 \mathrm{n}=13$ and 8 ; and at $400 \mathrm{nM} \mathrm{t}(4)=2.46, \mathrm{p}=0.03, \mathrm{n}=10$ and 
4). The EC50 of CP93129 increased from $33 \pm 4$ nM to $320 \pm 19$ nM. In contrast, baclofen $(600 \mathrm{nM})$ inhibition was unaffected by high $\mathrm{Ca}^{2+}$ concentration $(\mathrm{t}(16)=0.88, \mathrm{p}=0.38$; Fig. $1 \mathrm{Cc}$, Db). This latter result implies that $10 \mathrm{mM} \mathrm{Ca}^{2+}$ does not cause saturating $\mathrm{Ca}^{2+}$ entry with respect to neurotransmitter release, allowing reduced $\mathrm{Ca}^{2+}$ entry by baclofen to reduce $\mathrm{P}_{\mathrm{r}}$.

\section{Paired pulse ratios are modified by $G A B A_{B}$ receptors but not by $5-H T_{1 B}$}

Colocalized $\mathrm{GABA}$ B and $5-\mathrm{HT}_{1 \mathrm{~B}}$ receptors act at different targets $-\mathrm{Ca}^{2+}$ channels or the SNARE complex respectively - therefore their activation may evoke different effects on vesicle fusion. We measured paired pulse ratios (PPRs) to determine whether these receptors cause inhibition by a change in $\mathrm{P}_{\mathrm{r}}$ (Dobrunz and Stevens, 1997). As a control we raised the extracellular $\mathrm{Mg}^{2+}$ concentration (Del Castillo and Katz, 1954) from 1 to $4 \mathrm{mM}$ to reduce presynaptic $\mathrm{Ca}^{2+}$ entry and therefore $\mathrm{P}_{\mathrm{r}}$. In $4 \mathrm{mM} \mathrm{Mg}^{2+}$, the mean amplitude of the first EPSC was reduced (to $42 \pm 3 \%$ of control $n=14$, Fig. 2A), and the PPR (EPSC2/EPSC1) was increased by a factor of $1.64 \pm 0.09$, $\mathrm{n}=14$ (quantified in Fig. 2E, red) demonstrating a $\mathrm{Ca}^{2+}$ dependent reduction in $\mathrm{P}_{\mathrm{r}}$.

We inhibited EPSCs with baclofen (600nM, half maximal concentration; Fig. 2B) which reduced the first EPSC to $40 \pm 6 \%$ and enhanced PPRs (by $1.62 \pm 0.1, n=10$; quantified in Fig. $2 \mathrm{E}$, green) demonstrating an effect of $\mathrm{GABA}_{\mathrm{B}}$ receptors on $\mathrm{P}_{\mathrm{r}}$, consistent with our earlier work showing their effect on presynaptic $\mathrm{Ca}^{2+}$ entry (Hamid et al., 2014). The effect on PPR was concentration dependent (Fig. 2F) with a similar concentration response to the effect on EPSC amplitude.

As a negative control, AMPA receptor antagonism with half-maximal concentrations of the glutamate receptor antagonist kynurenate $(200 \mu \mathrm{M})$ showed no effect on PPRs. (Fig. 2C. The EPSC2/EPSC1 ratio was $1.13 \pm 0.04(n=19)$ of control (quantified Fig. 2E, gray). This is expected for postsynaptic targets. CP93129, inhibits CA1-subicular EPSCs presynaptically (Zurawski et al., 2019). Nevertheless, we now show a half-maximal CP93129 (50nM) 
concentration, which reduced the first EPSC to $54 \pm 4 \%$ of control, did not alter PPRs (PPR in CP93129 was $1.13 \pm 0.07$ of control; Fig. 2D,E, blue; $n=14)$. This lack of effect of CP93129 on PPRs was consistent over the full concentration response range of CP93129 on EPSCs (Fig. 2G).

A one way ANOVA to test effects of raised $\mathrm{Mg}^{2+}$ concentration, of baclofen, kynurenate and of CP93129 on PPRs (data from Fig. 2E), showed significance, ANOVA single factor $F(3,53)=$ 16.85, $\left.\mathrm{p}=8 \times 10^{-8}\right)$. Post-hoc Tukey HSD analysis revealed no significant difference between effects of raised $\mathrm{Mg}^{2+}$ and baclofen $(\mathrm{p}>0.1)$ and none between effects of kynurenate and CP93129 ( $p>0.1$ ). However, the effect of CP93129 was significantly different than lowering $P_{r}$ with raised $\mathrm{Mg}^{2+}(\mathrm{p}<0.001)$, or baclofen $(\mathrm{p}<0.001)$. Thus, effects of $5-\mathrm{HT}_{1 \mathrm{~B}}$ receptors are paradoxical, they are presynaptic but do not alter $P_{r}$, whereas $G A B A_{B}$ receptors which are also presynaptic do alter $P_{r}$.

\section{5-HT $T_{1 B}$ but not GABA $A_{B}$ receptors enhance low affinity block of AMPA EPSCs}

We investigated whether presynaptic receptors alter synaptic cleft glutamate concentrations at postsynaptic AMPA receptors. Partial block of EPSCs by a low affinity antagonist is caused by antagonist binding and unbinding. If the antagonist unbinds within the time-course of glutamate in the synapse, antagonist bound receptors will then become available for either glutamate or antagonist binding. Therefore, fractional low affinity antagonism of the AMPA receptor EPSC will depend on the glutamate concentration (Clements et al., 1992). EPSCs evoked by low glutamate cleft concentrations will be more completely antagonized than those at high concentrations.

To first determine any effect of a reduction in $\mathrm{P}_{\mathrm{r}}$ on cleft glutamate concentration, we recorded AMPA receptor EPSCs. The effect of lowering $\mathrm{P}_{\mathrm{r}}$ with high $\mathrm{Mg}^{2+}$ was tested against the efficacy of low affinity kynurenate antagonism. We compared kynurenate efficacy in control (1mM) and 
high ( $4 \mathrm{mM}) \mathrm{Mg}^{2+}$ concentrations in the same cell and stimulus intensity, because it is not clear that the mean control cleft glutamate concentrations were identical from cell to cell. After obtaining baseline EPSCs, we superfused the slice with kynurenate $(200 \mu \mathrm{M})$ to obtain a partial block of the EPSC (in the example to $70 \%$ of control; Fig. 3Aa, gray). Kynurenate was removed to re-measure control EPSCs. The $\mathrm{Mg}^{2+}$ concentration was then increased to $4 \mathrm{mM}$ to reduce $\mathrm{P}_{\mathrm{r}}$ (EPSC reduced to $69 \%$ of control, Fig. $3 \mathrm{Aa}$, red). Kynurenate $(200 \mu \mathrm{M})$ was reapplied in $4 \mathrm{mM}$ $\mathrm{Mg}^{2+}$ to measure its efficacy at a lower $\mathrm{P}_{\mathrm{r}}$. The EPSC in $4 \mathrm{mM} \mathrm{Mg}^{2+}$ was reduced by the same proportion as in control (to $67 \%$ of response in $4 \mathrm{mM} \mathrm{Mg}^{2+}$, Fig. 3Aa, purple). To compare inhibition by kynurenate in control and $4 \mathrm{mM} \mathrm{Mg}^{2+}$ the responses in $4 \mathrm{mM} \mathrm{Mg}^{2+}$ alone and combined with kynurenate were scaled to control amplitudes (Fig. 3Ab) showing similar proportionate inhibition. In repeat experiments the drug sequence was randomized. For all cells, in $1 \mathrm{mM} \mathrm{Mg}^{2+}$, kynurenate $(200 \mu \mathrm{M})$ reduced EPSCs to $44 \pm 4 \%$ of control, and in $4 \mathrm{mM} \mathrm{Mg}^{2+}$ kynurenate similarly reduced the EPSC to a not significantly different $43 \pm 4 \%(n=10$; Fig. $3 A c$, purple; paired Students t test, $\mathrm{t}(9)=0.39, \mathrm{p}=0.7)$.

We then assayed the efficacy of kynurenate inhibition before and in baclofen which will also alter $P_{r}$. In the example, kynurenate $(200 \mu \mathrm{M})$ reduced the mean EPSC amplitude to $62 \%$ of control (Fig. 3Ba, gray). In baclofen (600 nM; Fig. 3Ba, green) the inhibited EPSC was reprobed with kynurenate $(200 \mu \mathrm{M})$, which now reduced the EPSC to $61 \% \%$ of its amplitude in baclofen alone (Fig. 3Ba, dark green). Responses were again scaled to compare the effect of kynurenate in controls and in baclofen (Fig. 3Bb). In 19 experiments, kynurenate inhibited control responses to $46 \pm 3 \%$ and the inhibitory effect was slightly but signficantly less in baclofen, inhibiting to $51 \pm 3 \%$ (Fig. 3Bc; green; paired Students t test, $t(18)=2.19, p=0.04$ ).

We similarly assayed the efficacy of kynurenate block before and in CP93129, which did not alter $\mathrm{P}_{\mathrm{r}}$. In the example, kynurenate $(200 \mu \mathrm{M})$ reduced peak the EPSC amplitude to $55 \%$ of 
control (Fig. 3Ca, gray). After removal of kynurenate, EPSC amplitudes were recorded to reconfirm control responses. CP93129 (50nM) was applied (Fig. 3Ca, light blue), and the CP93129 inhibited EPSC was re-probed with kynurenate $(200 \mu \mathrm{M})$, which now reduced the EPSC to $38 \%$ of its amplitude in CP93129 alone (Fig. 3Ca, blue). Responses were again scaled to directly compare the effect of kynurenate in controls and in CP93129 showing an enhancement in inhibition (Fig 3Cb). In 17 experiments, kynurenate inhibited control responses to $57 \pm 3 \%$ and responses in CP93129 to $37 \pm 2 \%$. This latter inhibitory effect was signficantly greater than the effect of kynurenate alone (Fig. 3Cc; (paired Students t test, $t(16)=5.56, p=$ $\left.2.1 \times 10^{-5}\right)$.

As a negative control for the effect of CP93129 in kynurenate, we replaced the competitive antagonist (kynurenate) with a non-competitive AMPA receptor antagonist, GYKI52466 (GYKI). GYKI should inhibit EPSCs similarly, regardless of glutamate concentration because it does not compete with glutamate (Fig .3D). Mean inhibition by GYKI in control was to $63 \pm 4 \%$ and the efficacy of GYKI was slightly but significantly reduced in CP93129 ( $n=6$, to $68 \pm 4 \%$ of response in CP93129, paired Students $t$ test, $t(5)=3.85, p=0.011$ ). This result is small but may imply a slight bias in recordings of EPSC amplitudes as their amplitude is reduced by combined ligands. The result may indicate that we have slightly underestimated the effect of $5-\mathrm{HT}_{1 \mathrm{~B}}$ receptors on cleft glutamate concentrations, but does will not change the conclusion. This bias may also underlie the slight but not significant relative reduction in effect of kynurenate seen in baclofen (Fig $3 \mathrm{Bc}$ ).

The effects of high $\mathrm{Mg}^{2+}$, baclofen and CP93129 on the efficacy of kynurenate and the effect of CP93129 on the efficacy of GYKI on the inhibition of the synaptic responses were compared to one another by comparing the ratios of effects of antagonist (kynurenate or GYKI) with the same antagonist combined with either $4 \mathrm{mM} \mathrm{Mg}^{2+}$, with baclofen, or with CP93129 (Fig. 3E). All four experiments were compared with a one way ANOVA showing substantial significance $(F(3,48)=$ 
15.88, $\left.p=1.4 \times 10^{-6}\right)$. Post hoc Tukey's HSD analysis revealed that the the effect of baclofen was not significantly different than the effect of high $\mathrm{Mg}^{2+}$ on the efficacy of kynurenate inhibition $(p>0.1)$, This is consistent with inhibition mediated by a change in $P_{r}$ of univesicular events at each synapse. In contrast, the effect of CP93129 on kynurenate-mediated inhibition was significantly greater than that of $\mathrm{Mg}^{2+}(\mathrm{p}<0.005)$, baclofen $(\mathrm{p}<0.001)$ and of the effect of CP93129 on GYKI inhibition ( $p<0.005)$.

Single raised concentrations of $\mathrm{Mg}^{2+}(4 \mathrm{mM})$ or single concentrations of baclofen $(600 \mathrm{nM})$, or CP93129 (50nM) show varying degrees of inhibition from cell to cell. For example, initial effects of $50 \mathrm{nM}$ CP93129 reduced the EPSC from as little as to 0.8 of control to as much as 0.3 . If this variance reflects the efficacy of the agonist on cleft glutamate concentration it will correlate with amplification of agonist inhibition by kynurenate (shown in Fig. 3E). To test this we compared the efficacy of the agonist alone in each neuron (agonist/control), to the change in agonist efficacy by kynurenate [(kynurenate/control)/(agonist/kynurenate+agonist)]. We first plotted these for effects of high $\mathrm{Mg}^{2+}$ (Fig. 3F). There was no correlation between inibition by $4 \mathrm{mM} \mathrm{Mg}^{2+}$ with the subsequent effect of $\mathrm{Mg}^{2+}$ on kynurenate inhibition. This is consistent with $\mathrm{a} \mathrm{Mg}^{2+}$ induced change in $\mathrm{P}_{\mathrm{r}}$ at univesicular synapses causing no change in cleft glutamate concentration regardless of the initial efficacy of raised $\mathrm{Mg}^{2+}$. Similarly, there is no correlation between the efficacy of baclofen and its effect on subsequent kynurenate block (Fig. 3G). However, there is a strong correlation between the CP93129 efficacy and its amplification of kynurenate inhibition $(\mathrm{Fig} 3 \mathrm{H})$, indicating that the greater the effect of presynaptic $5-\mathrm{HT}_{1 \mathrm{~B}}$ receptors, the lower it drives cleft glutamate concentration and therefore the larger inhibitory effect of kynurenate. We conclude that changes in $\mathrm{P}_{\mathrm{r}}$ do not alter cleft glutamate concentrations, but $5-\mathrm{HT}_{1 \mathrm{~B}}$ receptors do.

It was important to determine that synaptic responses were not impacted by changes in whole cell recording access during the experiments. In all experiments, we monitored whole cell 
access by applying a small $(5 \mathrm{mV}, 20 \mathrm{~ms})$ test pulse before each evoked EPSC was recorded. An example is shown of this recording throughout a sequential application of kynurenate, and CP93129 and then the drugs combined simultaneously measuring effects on synaptic responses (Fig. 4A,B), while simultaneously monitoring whole cell series resistance calculated from double exponentials fitted to the settling of the step current (Fig. 4C). Experiments were terminated and data not used if access resistance changed by more than $20 \%$. For the examples used for analysis (Fig 4D), no signficant difference was seen for access impedance (ANOVA single factor $F(3,64)=0.065, p=0.97)$ or holding current $(F(3,64)=0.18, p=0.91$ ) when comparing between ligand applications.

\section{5-HT $T_{1 B}$ but not GABA $A_{B}$ receptors differentially inhibit AMPA and NMDA EPSCs}

Glutamate activates receptors with varying sensitivities: for example, AMPA, NMDA and metabotropic glutamate receptors have different affinities for glutamate and different numbers of glutamate binding sites. Consequently, changes in cleft glutamate concentration may differentially alter their activation (Choi et al., 2003; Schwartz et al., 2007; Gerachshenko et al., 2009). We compared 5- $\mathrm{HT}_{1 \mathrm{~B}}$ and $\mathrm{GABA} \mathrm{B}_{\mathrm{B}}$ receptor inhibition on AMPA and NMDA receptormediated synaptic responses. AMPA receptor-mediated EPSCs were recorded as before. We

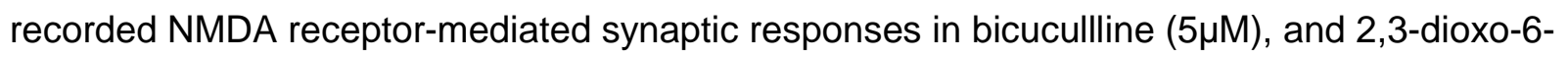
nitro-7-sulfamoyl-benzo[f]quinoxaline (NBQX; $5 \mu \mathrm{M})$ at a holding potential of $-35 \mathrm{mV}$. Baclofen (600nM) equally inhibited AMPA and NMDA components of EPSCs (Fig. 5A; to $49 \pm 6 \%, n=8$, and to $54 \pm 4 \%, n=6$ respectively; $t(12)=0.80, p=0.44)$. CP93129 (50nM) inhibited AMPA EPSCs significantly more than NMDA EPSCs (Fig. 5B; to $54 \pm 6 \%, n=10$, and to $93 \pm 4 \%, n=6$ respectively; $\left.t(14)=7.15, p=4.9 \times 10^{-6}\right)$. Concentration response curves of CP93129 inhibition of AMPA and NMDA EPSCs diverged (Fig. 5C). AMPA receptor-mediated EPSCs were maximally inhibited to $20 \pm 3 \%$ of control whereas NMDA receptor-mediated EPSCs were significantly less inhibited to $75 \pm 6 \%$ (paired Students $t$ test, $t(7)=6.48, p=0.00017$ ). We obtained similar 
results when we recorded NMDA and AMPA EPSCs simultaneously from the same synapses. AMPA and NMDA receptor-mediated responses were recorded simultaneously by holding the membrane potential at positive values and recording events early in the response or later. We measured AMPA receptor EPSC amplitudes within 2 ms of stimulation, whereas NMDA responses were measured during the decay after $100 \mathrm{~ms}$ (Fig. 5D) because these receptors show much slower decay kinetics than AMPA receptor mediated responses (Lester et al., 1990). In control conditions with no drugs, NMDA receptor EPSC amplitudes co-vary with those of AMPA receptors (Fig. 5E) indicating that the receptors are activated on the same synapses. In 6 neurons, we plotted the mean amplitudes of AMPA and NMDA receptor mediated EPSCs with increasing doses of CP93129. AMPA receptor EPSCs were inhibited to a significantly greater extent than were NMDA receptor EPSCs at all applied concentrations of CP93129 (Fig. $5 F)$. For the approximate half maximal concentration $(50 \mathrm{nM}) \mathrm{t}(5)=5.61, \mathrm{p}=0.002)$ and for the maximal concentration $(1000 \mathrm{nM}) \mathrm{t}(5)=7.52, \mathrm{p}=0.0007)$.

If the lack of effect of CP93129 on NMDA EPSCs is because it causes reduced cleft glutamate concentrations then an effect of CP93129 would be revealed by low affinity NMDA receptor antagonists that will amplify effects of changing glutamate concentrations at NMDA receptors (Choi et al., 2000). We recorded evoked pharmacologically isolated NMDA receptor EPSCs $(n=6)$ at $+50 \mathrm{mV}$ in bicuculline $(5 \mu M)$ and NBQX $(5 \mu M)$. Low doses of CP93129 (10 and 50nM) did not significantly reduce the EPSC in 6 neurons (ANOVA single factor $F(2,12)=3.80, p=0.052$; Fig. 5Ga, H). In a further 6 neurons the same experiment was performed in the low affinity competitive NMDA receptor antagonist L-5-amino pentanoic acid (L-AP5, $250 \mu \mathrm{M})$. The EPSC was reduced to $55 \pm 4 \%$ of control by L-AP5 (Fig. 5Gb, H). In L-AP5, CP93129 at both 10 and 50nM CP93129 now inhibited these partially blocked EPSCs to $66 \pm 7$ and $45 \pm 4 \%$ of the response in L-AP5 alone. These reductions were significant (ANOVA single factor $F(2,12)=7.22$, 
$\mathrm{p}=0.009$ ). Thus, NMDA receptors are exposed to a similar $5-\mathrm{HT}_{1 \mathrm{~B}}$ receptor-mediated reduction in glutamate concentration to that seen by AMPA receptors.

\section{The effect of $5-H T_{1 B}$ receptors on glutamate release}

It is possible to image glutamate release using genetically engineered glutamate sensors. To achieve this we virally infected subicular neurons with iGluSnFR using an AAV1 containing iGluSnFR.WPRE.SV40 under a human synapsin promotor (pAAV.hSyn.iGluSnFr.WPRE.SV40 (AAV5) (Marvin et al., 2013) by injecting the viral vector into hippocampi of 22 day rats . In hippocampal slices from these animals epifluorescence imaging (excitation $470 \mathrm{~nm}$, emission, $520 \mathrm{~nm}$ ) revealed fluorescent subicular pyramidal neurons. The slices were placed in a custom designed imaging chamber and a stimulation electrode placed as for electrophysiogical recording. The subicular region was then imaged using LLSM (Fig 6A). The light sheet penetrated to aproximately $50 \mu \mathrm{m}$ in the slice and time series images of single planes were captured with a single exposure time of $10 \mathrm{~ms}$ and a frame rate of $80 \mathrm{~Hz}$. The LLSM single frame was $512 \times 512$ pixels $(52 \times 52 \mu \mathrm{m})$ and within this multiple locations of release were resolved over a sequence of up to 21 individual stimuli at 5 second intervals (Fig 6B). Events were well-resolved using LLSM imaging (Fig 6C,D). To test the effect of presynaptic $5-\mathrm{HT}_{1 \mathrm{~B}}$ receptors on this glutamate release, CP93129 (100 nM) was applied (Fig 6D,E). Images were analyzed at 12 locations where events were evoked in controls from 4 animals. The probability of recording an event at the same location as in control was unchanged in CP93129 (0.20 \pm 0.02 ) vs $0.19 \pm 0.03$ in control (Fig $6 \mathrm{~F} ; \mathrm{t}(12)=0.17, \mathrm{p}=0.87)$. However. event amplitudes were significantly reduced to $24 \pm 6 \%$ of control $\left(t(12)=7.46, p=1.3 \times 10^{-5}\right)$ by CP93129 (Fig $\left.6 G\right)$. These data support for the hypothesis that presynaptic $5-\mathrm{HT}_{1 \mathrm{~B}}$ receptors modulate evoked amounts of neurotransmitter released at each synapse, but do not alter $\mathrm{P}_{\mathrm{r}}$.

\section{Simulating glutamate release and receptor activation}


$\mathrm{GABA}_{B}$ receptors reduce $\mathrm{P}_{r}$, whereas, 5- $\mathrm{HT}_{1 \mathrm{~B}}$ receptors lower cleft glutamate concentrations.

The latter may be due to a modification of the fusion pore during neurotransmitter release

(Harata et al., 2006; Photowala et al., 2006), changes in multivesicular release (Rudolph et al., 2015) or modulation of the location of release with respect to postsynaptic receptors (Tang et al., 2016; Chen et al., 2018; Haas et al., 2018). We created a Monte Carlo simulation of a simple synapse using MCell to probe these possibilities.

The simulated synapse comprised a disk-shaped synaptic cleft, $300 \mathrm{~nm}$ in diameter and $20 \mathrm{~nm}$ deep, with kinetically modeled AMPA (Robert and Howe, 2003) and NMDA receptors (Banke and Traynelis, 2003) placed on the postsynaptic surface (Fig 7). For each condition, 20 random seeds were simulated, whereby glutamate release was modeled from between one to three vesicles attached to the presynaptic surface with a dynamically opening pore (Multimedia File 1), initially with a $0.4 \mathrm{~nm}$ diameter and the length of two lipid bilayers. This is approximately the value proposed for the conductance of foot events in large dense core vesicles (Vardjan et al., 2007). The simulated pore then expanded to the full diameter of the vesicle over a range of timecourses from 0.2 to $20 \mathrm{~ms}$. We tested three hypotheses: 1) glutamate release was slowed through a fusion pore, 2) multivesicular vesicle numbers were reduced, 3) relative locations of release sites and receptors were altered. The parameter files for these simulations are available on our website (https://alford.lab.uic.edu/GPCRs.html). The individual parameters and sources are listed in Table 1.

To simulate a slowly opening fusion pore, the vesicle (containing 5000 glutamates) was attached to the presynaptic membrane through a pore (Fig. 7A). The simulated pore expanded to the diameter of the vesicle, but arrested at a diameter of $0.4,0.5,0.75,1.0,1.5$ or $2 \mathrm{~nm}$ for 20ms. Receptors were randomly seeded on the postsynaptic membrane, and their states represented by colors in kinetic models (Fig. 7D). Arresting the fusion pore opening at set diameters slowed release and reduced peak cleft glutamate concentrations (Fig. 7Ab) 
compared to full expansion of the pore to the diameter of the vesicle within $200 \mu \mathrm{s}$, which represents the default state. This slower glutamate release reduced simulated AMPA, but not NMDA receptor responses (Fig.7Ac-Ad) (Multimedia File 2). Both the peak simulated glutamate concentration and peak AMPA receptor activation were reduced with smaller pore sizes, whereas NMDA receptor responses remained unchanged (Fig 7. Ae-Af).

Multivesicular release was simulated by varying numbers of simulated fusing vesicles from 1 to 3 (Fig. 7B). One vesicle was placed at the center and two offset by 75nm (Fig. 7Ba). Fusion was simulated by pores fully opening in $200 \mu \mathrm{s}$. Vesicle content varied from 333 to 5000 glutamates because at high glutamate content the AMPA receptor response saturated with more than one vesicle, preventing any modulation. Varying vesicle numbers altered cleft glutamate concentration and modulated AMPA and NMDA receptor responses nearly equally (Fig. 7BbBd). The effect on both NMDA receptors and AMPA receptors was modulated by the total number of released glutamates rather than vesicle number (Fig 7Be-Bf).

To vary vesicle fusion position compared to receptors, receptors were seeded within two proscribed areas of the postsynaptic density; one under the fusing vesicle and the other a mean distance of $150 \mathrm{~nm}$ away (Fig. 7Ca). Release of 5000 glutamates was simulated with complete fusion in $200 \mu$ s causing peak glutamate concentrations that differed at the two sites. Little modulation of AMPA or NMDA receptor responses occurred (Fig. 7Cc-Cd). Earlier work simulating vesicles displaced from the release site reported larger effects with fewer released glutamates (Haas et al., 2018). Consequently, the simulation was repeated with 1500 glutamates (Fig. 7Cf-Ch). The more distant clusters of AMPA and NMDA receptor responses were reduced to $80 \%$ and $83 \%$ of the amplitude under the release site respectively. Thus, the response is sensitive to relative locations of vesicle fusion and receptor location, but this effect is small compared to that of experimental $5-\mathrm{HT}_{1 \mathrm{~B}}$ or $\mathrm{GABA} \mathrm{B}_{\mathrm{B}}$ receptor activation and does not recapitulate the difference in effect between AMPA and NMDA receptor responses. Overall, 
changing fusion pore dilation best mimicked the physiological effect of $5-\mathrm{HT}_{1 \mathrm{~B}}$ receptor activation.

\section{Simulating the amplification of inhibition by kynurenate}

Experimental effects of the low affinity antagonist, kynurenate, on AMPA receptor EPSCs indicate that $5-\mathrm{HT}_{1 \mathrm{~B}}$ receptors, but not $\mathrm{GABA}_{\mathrm{B}}$ receptors, lower the concentration of glutamate in the synaptic cleft. To determine whether kynurenate might discriminate between mechanisms by which cleft glutamate concentration is changed based on receptor effects, we simulated the action of kynurenate using a modification of the kinetic model of the AMPA receptor.

The kinetic model assumed that kynurenate can substitute for glutamate at all states of the receptor but prevented receptor channel opening (Fig. 8Aa). Simulations were performed with kynurenate $(240 \mu \mathrm{M})$ present in the synaptic cleft. This reduced the simulated AMPA receptormediated response to $55 \%$ of control (Fig. $8 \mathrm{Ab}$ ). The simulations were then repeated with the synaptic vesicle fusion pore diameter arrested for $20 \mathrm{~ms}$ at diameters from 0.4 to $1.5 \mathrm{~nm}$. The effect of kynurenate was enhanced when the pore size was restricted (Fig. 8B). The effect of simulated kynurenate was also tested against multivesicular release. Modifying the number of fused vesicles was only effective at a reduced number of glutamates present in each vesicle, thus, these simulations were performed from with three, two or one vesicles each containing 700 glutamates as for Fig 7Bb-d. Kynurenate also enhanced the effect of reduced vesicle number on the simulated AMPA receptor response (Fig. 8C).

Effects of both these manipulations were compared to the experimental effects of $\mathrm{GABA}_{\mathrm{B}}$ and 5$\mathrm{HT}_{1 \mathrm{~B}}$ receptor activation on AMPA mediated synaptic responses. Box plots (from Fig. 3E) showing CP93129 and baclofen effects on kynurenate mediated antagonism are presented alongside simulated kynurenate inhibition following a change in number of fusing vesicles (normalized to the maximum - 3) and following arrest of the fusion pore at between 0.4 and 1.5 $\mathrm{nm}$ diameters normalized to full fusion (defined as complete opening of the fusion pore the 
vesicle diameter in $200 \mu \mathrm{s})$. Both of these manipulations enhanced the efficacy of kynurenate (Fig. 8D).

As for the experimental effects of agonists (Fig 3E,H), simulations of variation in inhibition of the AMPA response, either by varying the number of multivesicular fusing vesicles at one active zone (Fig. 8D orange) or varying the vesicle pore diameter (Fig. 8D purple) correlated with the enhancing effect of kynurenate on both manipulations (Fig. 8E). Both approaches recapitulated experimental effects of CP93129 but not of baclofen (Fig. 8E). From this combination of experimental effects of low affinity antagonist, and its simulation, the experimental data can be explained by a reduction synaptic cleft glutamate. Results with kynurenate alone, however, do not discriminate between the effect on release, whether change in fusion pore diameter or change in fusing vesicle numbers that causes this change in concentration.

\section{Modulation of the timecourse of the AMPA receptor mediated response}

Slowing fusion pore opening slowed the rise and decay times of the simulated AMPA receptor response (see Fig. 7Ac) demonstrated by replotting the inhibited response scaled to the peak of the control (Fig. 9A). In simulated data, the arrested pore diameter $(0.4 \mathrm{~nm})$ increased the timecourse $(\tau)$ of the rise from 0.09 to $0.35 \mathrm{~ms}$ and of the decay from 0.97 to $1.59 \mathrm{~ms}$ measured by single exponentials fitted to the rise and decay. Simulated kinetic properties of AMPA receptor opening are more rapid than those experimentally obtained. This may be because they are neither affected by dendritic filtering nor by asynchronous vesicle fusion. Nevertherless, we investigated effects of agonist on the kinetics of synaptic responses.

Responses from 11 neurons were recorded in which EPSCs showed monotonic decays (Fig. 9B). CP93129 (50nM) increased $\tau$ 's of rise and decay phases, visible when the response in CP93129 was scaled to the control amplitude (Fig. 9Bb). Single exponential fits to the 10 to $90 \%$ risetimes showed a significant increase from a mean of 1.4 to $2.0 \mathrm{~ms}(\mathrm{t}(10)=3.06$, $\mathrm{p}=0.006)$ as did the decay times from 7.3 to $9.4 \mathrm{~ms}(\mathrm{t}(10)=3.54, \mathrm{p}=0.003)$ (Fig.9B). 
Simulations of reduction of $\mathrm{P}_{\mathrm{r}}$ between synapses is trivial - a reduction in numbers of sites consequently kinetic properties of the simulated EPSC are unchanged (Fig. 9C, left panel). Alternatively, a simulated reduction in $\mathrm{P}_{\mathrm{r}}$ at a multivesicular synapse shows a slight decrease in decay rate (Fig. 9C, right hand panel). We compared this to effects of baclofen $(1 \mu \mathrm{M})$, which reduces $P_{r}$, in 10 neurons, again in which the decay was monotonic. Baclofen had no significant effect on mean rise time (control $=1.56 \pm 0.12 \mathrm{~ms}$, baclofen $=1.44 \pm 0.16 \mathrm{~ms} ; \mathrm{t}(9)=0.83, p=0.21$ ) or decay (control=7.92 $\pm 0.47 \mathrm{~ms}$, baclofen $=8.11 \pm 0.41 \mathrm{~ms} ; \mathrm{t}(9)=0.59, \mathrm{p}=0.30)$ (Fig.9D). These results emphasize that $5-\mathrm{HT}_{1 \mathrm{~B}}$ and $\mathrm{GABA}$ receptors on the same presynaptic terminals mediate inhibition by different mechanisms.

\section{Repetitive stimulation and train-dependent responses}

At the same terminals, $\mathrm{GABA}$ receptors inhibit $\mathrm{Ca}^{2+}$ entry, whereas $5-\mathrm{HT}_{1 \mathrm{~B}}$ receptors cause G $\beta \gamma$ to interfere with $\mathrm{Ca}^{2+}$-synaptotagmin SNARE complex interactions (Hamid et al., 2014). This implies selective effects of receptor activation, but also synergy following activation of both receptors (Zurawski et al., 2019). As presynaptic $\mathrm{Ca}^{2+}$ accumulates during stimulus trains (Yoon et al., 2007; Hamid et al., 2014) that induce long term plasticity (O'Keefe, 1990), it may modify

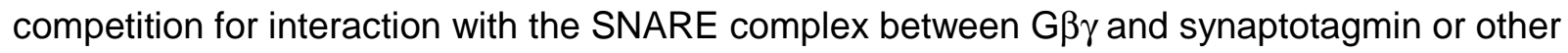
$\mathrm{Ca}^{2+}$ sensors such as Doc2 (Groffen et al., 2006) (Groffen et al., 2006) or synaptotagmin 7 (Jackman et al., 2016; Jackman and Regehr, 2017).

$\mathrm{GABA}_{\mathrm{B}}$ receptors inhibit train dependent $\mathrm{Ca}^{2+}$ accumulation. To show this, we recorded $\mathrm{Ca}^{2+}$ transients in CA1 pyramidal neuron terminals by filling the axons with $\mathrm{Ca}^{2+}$ sensitive dyes. CA1 neurons were whole cell recorded under current clamp with a red dye (Alexa 594) to determine the axon location and $\mathrm{Ca}^{2+}$ sensitive dye (Fluo 5F) to record action potential evoked $\mathrm{Ca}^{2+}$ transients. We have previously shown that Fluo $5 \mathrm{~F}$ allows reliable recording of $\mathrm{Ca}^{2+}$ signals over long periods (Hamid et al., 2014; Hamid et al., 2019). Individual presynaptic varicosities in the subiculum were imaged using line scanning $(500 \mathrm{~Hz})$ and neurons stimulated with $2 \mathrm{~ms}$ 
depolarizing current pulse trains (5 stimuli at 20 ms intervals) to evoke action potentials (Fig $10 \mathrm{~A}$, upper trace). Line scanning resolved $\mathrm{Ca}^{2+}$ transients over accumulating $\mathrm{Ca}^{2+}$ during the stimulus train (Fig 10Aa, lower trace). Baclofen $(600 \mathrm{nM})$ reduced both the differential immediate increase in the amplitude of each evoked event in the train (Fig 10Ac, closed circles) as well as the cumulative sum of the $\mathrm{Ca}^{2+}$ transient following each stimulus (Fig 10Ac, open squares).

Consequently, we hypothesized that modifying $\mathrm{Ca}^{2+}$ entry with $\mathrm{GABA}_{\mathrm{B}}$ receptors will alter the efficacy of $5-\mathrm{HT}_{1 \mathrm{~B}}$ receptors during repetitive activity to provide a form of metamodulation and synaptic integration.We examined effects of stimulus trains (4 shocks, $50 \mathrm{~Hz}$ ) on inhibition. AMPA EPSCs were isolated in bicuculline and D-AP5. Baclofen inhibited AMPA EPSCs (measured from EPSC initial slopes) throughout these trains with no significant difference in inhibition between responses within the train (Fig. 10B; ANOVA single factor $F(3,20)=28.2$, $\mathrm{p}=0.18)$. In CP93129 (100nM) initial slopes of the $1^{\text {st }}$ responses were reduced to $42 \pm 3 \%$ of control, while the $4^{\text {th }}$ only to $78 \pm 9 \%$ (Fig. 10C; single factor ANOVA determined whether CP93129 differentially altered EPSCs in the train - this was significant, ANOVA single factor $\left.F(3,40)=28.2, p=5.7 \times 10^{-10}\right)$. Post hoc Tukey HSD analysis demonstrated the $3^{\text {rd }}$ and $4^{\text {th }}$ EPSCs were inhibited significantly less than the $1^{\text {st }}(p<0.001)$. No significant inhibition of NMDA EPSCs isolated in bicuculine $(5 \mu \mathrm{M})$ and NBQX $(5 \mu \mathrm{M})$ was recorded for any stimulus (Fig. 10D; ANOVA single factor $F(3,16)=0.36, p=0.78)$.

\section{GPCRs filter the final output of the hippocampus}

$\mathrm{GABA}_{B}$ receptors provide fairly uniform inhibition of synaptic output during stimulus trains after the second stimulus (Fig. 10B), when paired pulse facilitation associated with changes in $\mathrm{P}_{\mathrm{r}}$ is increased. By contrast, $5-\mathrm{HT}_{1 \mathrm{~B}}$ receptor activation reveals a complex modification of synaptic outputs from the hippocampus. NMDA receptor-mediated EPSCs are barely effected, though invivo activation of the NMDA responses would require depolarization, which can be provided by 
synaptic transmission via AMPA receptors. AMPA receptor responses are blocked at the start but not the end of short stimulus trains. If $5-\mathrm{HT}_{1 \mathrm{~B}}$ receptor activation merely inhibited AMPA receptor responses then synaptically evoked depolarization would be blocked and NMDA receptors would remain blocked by $\mathrm{Mg}^{2+}$. Therefore, we first determined how $5-\mathrm{HT}_{1 \mathrm{~B}}$ receptors modify information flow between CA1 and subicular neurons during activity trains in which AMPA receptor-mediated depolarization triggers NMDA receptor-mediated responses (Herron et al., 1986).

We stimulated CA1 axons with short stimulus trains as earlier but recorded from subicular neurons under current clamp conditions. Stimulation intensity was adjusted (up to $20 \mu \mathrm{A}$ ) to ensure that the first stimulus of the burst invariably caused an action potential in the recorded postsynaptic cell (Fig 11Aa). We found a complex mode of inhibition, mediated by CP93129. After application of the agonist, the first EPSP is significantly inhibited, leading to a dosedependent delay in depolarization and consequent firing of an action potential (Fig 11A-D), but CP93129 did not prevent action potential firing during the train, even at saturating concentrations. The mean number of APs following the first stimulus in 4 cells was $1.3 \pm 0.2$ in control, but reduced to $0.2 \pm 0.1$ by a half maximal concentration of CP93129 (50nM, $\mathrm{p}<0.05$, Fig.11Ea). However, firing recovered by the $2^{\text {nd }}$ stimulus, in which the control stimulus evoked 1.1 \pm 0.4 APs and stimuli in CP93129, evoked $1.1 \pm 0.4$ (Fig.11Eb), while by the $3^{\text {rd }}$ stimulus, evoked APs were enhanced by CP93129 (from $0.4 \pm 0.2$ to $0.7 \pm 0.3$, increase in number from ${ }^{\text {st }}$ to $3^{\text {rd }}$ was significant, $p<0.01$ ). Thus, while we see a concentration-dependent CP93129-evoked delay of APs (Fig.11A-D). The mean area under the depolarization is barely altered $(86 \pm 5 \%$ of control at $1 \mu \mathrm{M})$, even when the first AMPA receptor-mediated response is substantially inhibited (to $10 \pm 2 \%$, Fig.11F). This reflects the frequency-dependent recovery from $5-\mathrm{HT}_{1 \mathrm{~B}}$ receptormediated inhibition and lack of a CP93129 effect on NMDA receptor-mediated EPSCs. 
Baclofen inhibits EPSCs throughout trains (Fig.10B), and have previously been shown to act by inhibiting $\mathrm{Ca}^{2+}$ entry (Hamid et al., 2014). This implies it can modify $\mathrm{Ca}^{2+}$-synaptotagmin competition with Gßr at SNARE complexes and consequently meta-modulate effects in CP93129 which causes Gßy competition with Ca-synaptotagmin at SNARE complexes (Yoon et al., 2007). We investigated combined receptor activation on presynaptic modulation. Baclofen $(1 \mu \mathrm{M})$ Inhibited AMPA receptor EPSCs uniformly during stimulus trains (Fig.11Ga - green). However, in baclofen, CP93129 now also inhibits EPSCs throughout the train (Fig.11Ga,Gb purple). This meta-modulation of CP93129 inhibition by baclofen depends on the initial efficacy of baclofen. Plotting initial effects of baclofen alone against CP93129 inhibition of the last EPSC in the train in baclofen, reveals a linear relationship (Fig.11GC). This is consistent with $G A B A_{B}$ receptor inhibition of $\mathrm{Ca}^{2+}$ channels reducing $\mathrm{Ca}^{2+}$ that causes evoked release at each stimulus and for $\mathrm{Ca}^{2+}$-synaptotagmin competition with $5-\mathrm{HT}_{1 \mathrm{~B}}$ receptor released $\mathrm{G} \beta \gamma$ at SNARE complexes.

We tested this effect of baclofen on CP93129 filtering of EPSP trains. We did not evaluate specific effects of baclofen alone because polysynaptic inhibition is also altered by baclofen and these current clamp experiments included no $\mathrm{GABA}_{\mathrm{A}}$ antagonists. Nevertheless, recordings in baclofen provided a starting condition to test effects of CP93129 during trains after partial inhibition of presynaptic $\mathrm{Ca}^{2+}$ entry by baclofen (Fig. $11 \mathrm{Ha}$ ). CP93129 in baclofen reduced the area under the depolarization throughout the train (Fig. $11 \mathrm{Hb})$, such that in contrast to the effects of CP93129 alone, in baclofen CP93129 equally inhibited the first EPSP slope and the area under the depolarization during the train. Changes in area and initial slope are not significantly different at 50 or 400nM CP93129 (Fig. $11 \mathrm{H} \mathrm{t}(7)=1.45, \mathrm{p}=0.19$ and $\mathrm{t}(3)=1.39$, $p=0.252$ respectively). Thus, different receptors with different effectors inhibit release with different temporal outcomes through train evoked responses, but they also interact such that 
one receptor $\left(G A B A_{B}\right)$ alters the effect of a second $\left(5-\mathrm{HT}_{1 \mathrm{~B}}\right)$ both qualitatively and quantitatively causing an entirely novel form of presynaptic integration.

\section{Discussion}

Two pathways mediate GPCR-dependent membrane-delimited presynaptic inhibition. $\mathrm{G} \beta \gamma$ inhibits presynaptic $\mathrm{Ca}^{2+}$ entry or competes with $\mathrm{Ca}^{2+}$-synaptotagmin at the SNAP-25 cterminal in SNARE complexes. A third mechanism is possible, whereby neuromuscular miniature endplate potential frequency is reduced (Silinsky, 1984). Similarly a mechanism independent of $\mathrm{Ca}^{2+}$ entry or interaction with the SNAP-25 c-terminus inhibits miniature EPSCs in hippocampal CA1 neurons (Rost et al., 2011). $\mathrm{G}_{\mathrm{i} / \mathrm{o}}$ coupled $\mathrm{GABA}$ B receptors cause presynaptic inhibition throughout the CNS (Dutar and Nicoll, 1988; Alford and Grillner, 1991).

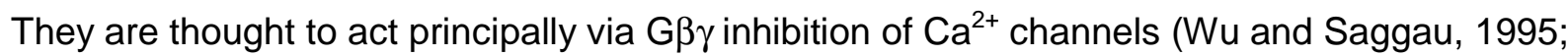
Hamid et al., 2014), although, in the nucleus accumbens, they target SNARE complexes (Manz et al., 2019). Understanding their function is important given use of baclofen in disorders such as multiple sclerosis, cerebral palsy, spinal injury and stroke.

Serotonin also modulates central excitability, and $5 \mathrm{HT} 1$ receptors are found presynaptically. 5- $\mathrm{HT}_{1 \mathrm{~B}}$ receptors control glutamate (Zifa and Fillion, 1992; Sari, 2004) and 5-HT (Davidson and Stamford, 1995) release, and may play a role in delayed action of Selective Serotonin Reuptake Inhibitors (SSRI) (Svenningsson et al., 2006; Tiger et al., 2018), in anxiety and depression (Nautiyal et al., 2016). Nevertheless, their presynaptic effects remain mostly undetermined. Two presynaptic targets have been found. In the Calyx of Held, they reduce $\mathrm{Ca}^{2+}$ entry (Mizutani et al., 2006), and In lamprey, they modify synaptotagmin-SNARE interactions (Blackmer et al., 2001; Blackmer et al., 2005; Gerachshenko et al., 2005). GABA ${ }_{B}$ and 5-HT $1 \mathrm{~B}$ receptors colocalize at CA1 pyramidal neuron presynaptic terminals (Boeijinga and Boddeke, 1993; Hamid et al., 2014) where 5-HT 1 r receptors cause G $\beta \gamma$-SNAP-25 interactions in SNARE 
complexes, and $\mathrm{GABA}_{\mathrm{B}}$ receptors inhibit $\mathrm{Ca}^{2+}$ entry (Hamid et al., 2014; Zurawski et al., 2019). Why receptors colocalize to cause presynaptic inhibition via different mechanisms may depend on their intersecting signaling mechanisms.

Presynaptic GPCR targets determine their effects on neurotransmission. For example, inhibition of $\mathrm{Ca}^{2+}$ channels reduces $\mathrm{P}_{\mathrm{r}}$. Consistent with this in $\mathrm{CA} 1$ terminals, $\mathrm{GABA}_{\mathrm{B}}$ receptors enhance PPR, but leave synaptic glutamate concentration unaffected. They also equally inhibit NMDA and AMPA responses. In contrast, 5- $\mathrm{HT}_{1 \mathrm{~B}}$ receptor effects are inconsistent with change in $\mathrm{P}_{\mathrm{r}}$. They leave PPRs unaffected, do not modify presynaptic $\mathrm{Ca}^{2+}$ entry (Hamid et al., 2014), but inhibit neurotransmission. Therefore, we investigated variations in cleft glutamate.

We find that changing $\mathrm{P}_{\mathrm{r}}$ with $\mathrm{Mg}^{2+}$ or baclofen did not alter evoked synaptic cleft glutamate concentration, whereas $5-\mathrm{HT}_{1 \mathrm{~B}}$ receptors did. We also found that $5-\mathrm{HT}_{1 \mathrm{~B}}$ receptors inhibit AMPA receptor-mediated EPSCs much more than NMDA receptor responses. Low affinity antagonism of NMDA receptors supports the conclusion that cleft glutamate concentrations fall after activation of $5-\mathrm{HT}_{1 \mathrm{~B}}$ receptors. This might be expected to alter miniature EPSC (mEPSC) amplitudes, however clear results are unlikely for two reasons. Glutamatergic inputs to subicular pyramidal neurons come from a mixed population and only CA1 neuron inputs express $5-\mathrm{HT}_{1 \mathrm{~B}}$ receptors. In addition, $\mathrm{G} \beta \gamma$ released from $5-\mathrm{HT}_{1 \mathrm{~B}}$ receptors competes with the $\mathrm{Ca}^{2+}$ sensor synaptotagmin 1 to reduce release. Ca-Synaptotagmin 1 does not evoke mEPSCs (Pang et al., 2011; Vyleta and Smith, 2011), therefore, we would not expect to see effects of G $\beta \gamma$ against mEPSCs. It is possible that other $\mathrm{Ca}^{2+}$ sensor/SNARE interactions are altered by G $\beta \gamma$ to mediate these effects (Yoon et al., 2008), but we have no evidence of this at these synapses. However, using iGluSnFR to visualize evoked glutamate release events revealed that $5-\mathrm{HT}_{1 \mathrm{~B}}$ receptors reduced the total amount of glutamate released, but not the probability of these events. We should note however, that analysis of the kinetic profile of these fluorescence transients likely will not resolve the kinetic release of glutamate. The iGluSnFR 
sensor used was able to detect events at high signal to noise, but the timing and size of events suggest it detected spillover glutamate from the synaptic cleft. At least three explanations exist for these findings. (1) 5-HT reduces $\mathrm{P}_{\mathrm{r}}$ in synapses where multivesicular release predominates (Rudolph et al., 2015) and simultaneous fusion of multiple vesicles are linked (Singer et al., 2004). In this scenario a change in $\mathrm{P}_{r}$ by 5 - $\mathrm{HT}$ is hidden by de-linking simultaneous fusion of multiple vesicles. (2) 5-HT modifies subsynaptic locations of release (Biederer et al., 2017; Chen et al., 2018). (3) A change in synaptic vesicle fusion mode.

We investigated these possibilities with experiments and simulations. We constructed Monte Carlo simulations of neurotransmitter release, its cleft diffusion, and activation of kinetic models of AMPA and NMDA receptors. Simulations either changed numbers of vesicles fusing at an active zone, altered the position of fusing vesicles with respect to postsynaptic receptors, or fusion pore timing. All these affected postsynaptic simulations of AMPA receptor activation. However, missalignment of fusion and receptors showed only small differential effects on AMPA and NMDA receptor responses. Multivesicular release can govern cleft glutamate concentrations. This has been shown by investigating effects of repetitive stimulation on $\mathrm{P}_{\mathrm{r}}$ (Foster et al., 2005; Christie and Jahr, 2006). Experimentally, we did not see change in glutamate cleft concentrations mediated by paired pulse stimulation to enhance $P_{r}$, or by reducing $\mathrm{P}_{\mathrm{r}}$ with raised $\mathrm{Mg}^{2+}$ or baclofen. This implies that putative effects of $5-\mathrm{HT}_{1 \mathrm{~B}}$ receptors on MVR would be more complex than a change in $\mathrm{P}_{\mathrm{r}}$. In simulations we found that altering the number of vesicles fusing caused little differential effects between AMPA and NMDA receptors. This contrasts with experimental results of $5-\mathrm{HT}_{1 \mathrm{~B}}$, but not $\mathrm{GABA}_{\mathrm{B}}$ receptor activation. Our simulations favored $5-\mathrm{HT}_{1 \mathrm{~B}}$ receptor-mediated effects on fusion pore dilation and duration and on $\mathrm{P}_{\mathrm{r}}$ for $\mathrm{GABA}_{\mathrm{B}}$ receptors. Although the simulation does not account for all properties of biological fusion pores, such as charges lining a pore, or flickering (Chang et al., 2017), it is notable that sustaining a $0.4 \mathrm{~nm}$ pore best simulated experimental results. Biophysical data predict a similar fusion pore diameter prior to expansion to full fusion (Vardjan et al., 2013). 
This conclusion is supported by experimental and simulated effects on response kinetics. Activation and decay rates following simulated arrested fusion pores were consistent with effects of $5-\mathrm{HT}_{1 \mathrm{~B}}$ receptors which similarly slowed EPSCs. In contrast, simulation of changes in fusion probability, at multivesicular or between univesicular synapses, sped up the decay rate or left it unchanged while baclofen had no effect on ESPC kinetics. By targeting the release machinery, 5- $\mathrm{HT}_{1 \mathrm{~B}}$ receptors cause selective changes in postsynaptic receptor activation. They are ineffective inhibitors of NMDA EPSCs. This is an effect previously ascribed to kiss-and-run fusion releasing sufficient glutamate to activate NMDA but not AMPA receptors (Choi et al., 2003; Photowala et al., 2006; Schwartz et al., 2007; Gerachshenko et al., 2009).

High $\mathrm{Ca}^{2+}$ concentrations allow synaptotagmin to competitively prevent $\mathrm{G} \beta \gamma$-SNARE complex binding, causing $\mathrm{Ca}^{2+}$-dependent loss of $\mathrm{G} \beta \gamma$-mediated presynaptic inhibition in lamprey (Yoon et al., 2007). Presynaptic $\mathrm{Ca}^{2+}$ accumulates during repetitive stimulation (Charlton et al., 1982; Swandulla et al., 1991). Thus if 5-HT $1 \mathrm{~B}$ receptors act by competing with $\mathrm{Ca}^{2+}$-synaptotagmin binding to SNARE complexes, whether synaptotagmin 1 or a fusogenic protein like synaptotagmin 7 (Jackman et al., 2016), we predict loss of 5-HT-mediated inhibition during repetitive stimulation. Indeed, we demonstrate that $5-\mathrm{HT}_{1 \mathrm{~B}}$ receptor mediated inhibition is prevented at high $\mathrm{Ca}^{2+}$ concentrations and during repetitive stimuli. This suggests that $5-\mathrm{HT}_{1 \mathrm{~B}}$ receptors filter synaptic transmission with an outcome similar to a silent synapse (Liao et al., 1995). This prevents stray single action potential transmission mediated by AMPA receptors. However, high frequency stimuli, such as theta bursts, transmit efficiently.

\section{Conclusions}

The sensitivity of $5-\mathrm{HT}_{1 \mathrm{~B}}$ receptor effects to $\mathrm{Ca}^{2+}$ accumulation and their lack of effect on NMDA responses are evident from current clamp recordings of subicular neurons during high frequency stimulation. 5- $\mathrm{HT}_{1 \mathrm{~B}}$ receptors inhibit early responses in stimulus trains, but burst stimulation allows recovery. Because NMDA receptor-mediated responses are much less 
inhibited, they are recruited during burst evoked depolarizations, when during the first stimulation NMDA receptor-mediated responses are blocked by $\mathrm{Mg}^{2+}$, but the receptor remains activated. Because the NMDA response is slow (Dale and Roberts, 1985; Lester et al., 1990), NMDA receptors are available for gating immediately following frequency-dependent release of inhibition of AMPA EPSPs and depolarization even after activation of presynaptic $5-\mathrm{HT}_{1 \mathrm{~B}}$ receptors. We show that $5-\mathrm{HT}_{1 \mathrm{~B}}$ receptors change the profile of transmission of synaptic trains. They allow train stimuli to be transmitted, but reject responses to single stimuli. It is interesting that 5- $\mathrm{HT}_{1 \mathrm{~B}}$ knockout mice display compromised working memory (Buhot et al., 2003), and reduced behavioral inhibition to novel stimuli, and learning is compromised in SNAP-25 $\Delta 3$ mice

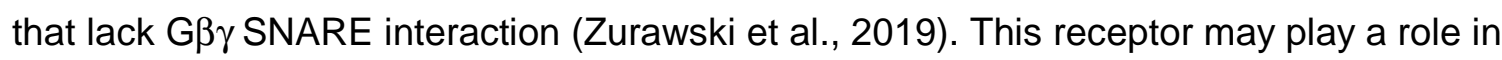
behaviors requiring impulse control; for example $5-\mathrm{HT}_{1 \mathrm{~B}}$ receptor knock-out animals are more motivated to self-administer cocaine (Rocha et al., 1998). Perhaps 5- $\mathrm{HT}_{1 \mathrm{~B}}$ receptors selectively process information in the face of competing stimuli.

In contrast, $\mathrm{GABA}_{\mathrm{B}}$ receptors inhibit $\mathrm{Ca}^{2+}$ entry. This implies interaction between the receptors. Indeed, low doses of baclofen modify temporal effects of CP93129 to prevent traindependent recovery from CP9129's inhibition, showing that coactivation of the receptors integrates information. Even weak $\mathrm{GABA}_{B}$ receptor activation prevents train dependent recovery from $5-\mathrm{HT}_{1 \mathrm{~B}}$ receptor activation. Thus, colocalization of presynaptic receptors responding to different agonists but whose signaling pathways converge and interact allows presynaptic terminals to act as sites of neural integration. 
Figure 1. Presynaptic 5-HT $1 B$ and $G A B A_{B}$ receptors inhibit evoked transmission from CA1 pyramidal neurons
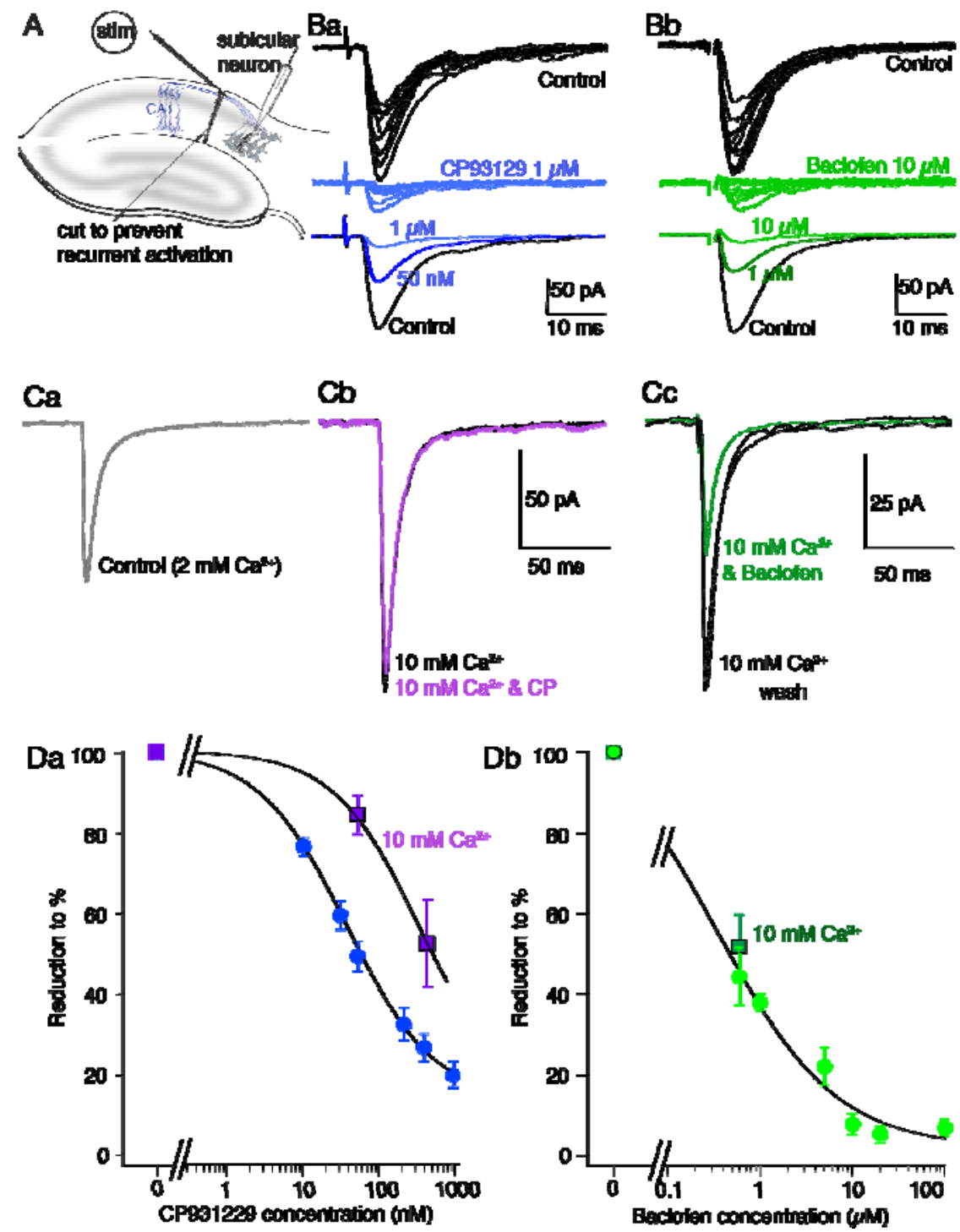

A) Subicular pyramidal neurons were whole cell patch clamped. CA1 pyramidal axons were stimulated with a monopolar, glass-coated tungsten microelectrode. The tissue was cut at the CA1/subiculum boundary to prevent recurrent excitation.

$\mathrm{Ba})$ Ten consecutive AMPA receptor-mediated EPSCs from a cell recorded in bicuculline $(5 \mu \mathrm{M})$ and D-AP5 $(50 \mu \mathrm{M})$ in control (black) and in CP93129 (blue). Means of responses in control 
(black) $50 \mathrm{nM}$ (dark blue) and 1 MM CP93129 (blue) are shown below.

Bb) Similar evoked EPSCs were recorded in control (black) and baclofen (10 $\mu \mathrm{M})$ green and means of EPSCs in control and in baclofen $(1 \mu \mathrm{M}$, dark green) and $10 \mu \mathrm{M}$ (green).

C) Synaptic responses recorded in control $(\mathrm{Ca})$ after addition of $10 \mathrm{mM} \mathrm{CaCl}_{2}(\mathrm{Cb}$, black) and with CP93129 (50 nM, purple). In raised extracellular $\mathrm{Ca}^{2+}(\mathrm{Cc})$ baclofen $1 \mu \mathrm{M}$ inhibited the synaptic response as for controls.

D) Concentration responses for (Da) CP93129 in control saline (blue circles) and in $10 \mathrm{mM}$ $\mathrm{CaCl} 2$ (purple squares) and (Db) Baclofen in control saline (light green circles) and in $10 \mathrm{mM}$ $\mathrm{CaCl}_{2}$ (dark green square). 
Figure 2. $P_{r}$ is unaffected by $5-H T_{1 B}$ but reduced by $G A B A_{B}$ receptor activation
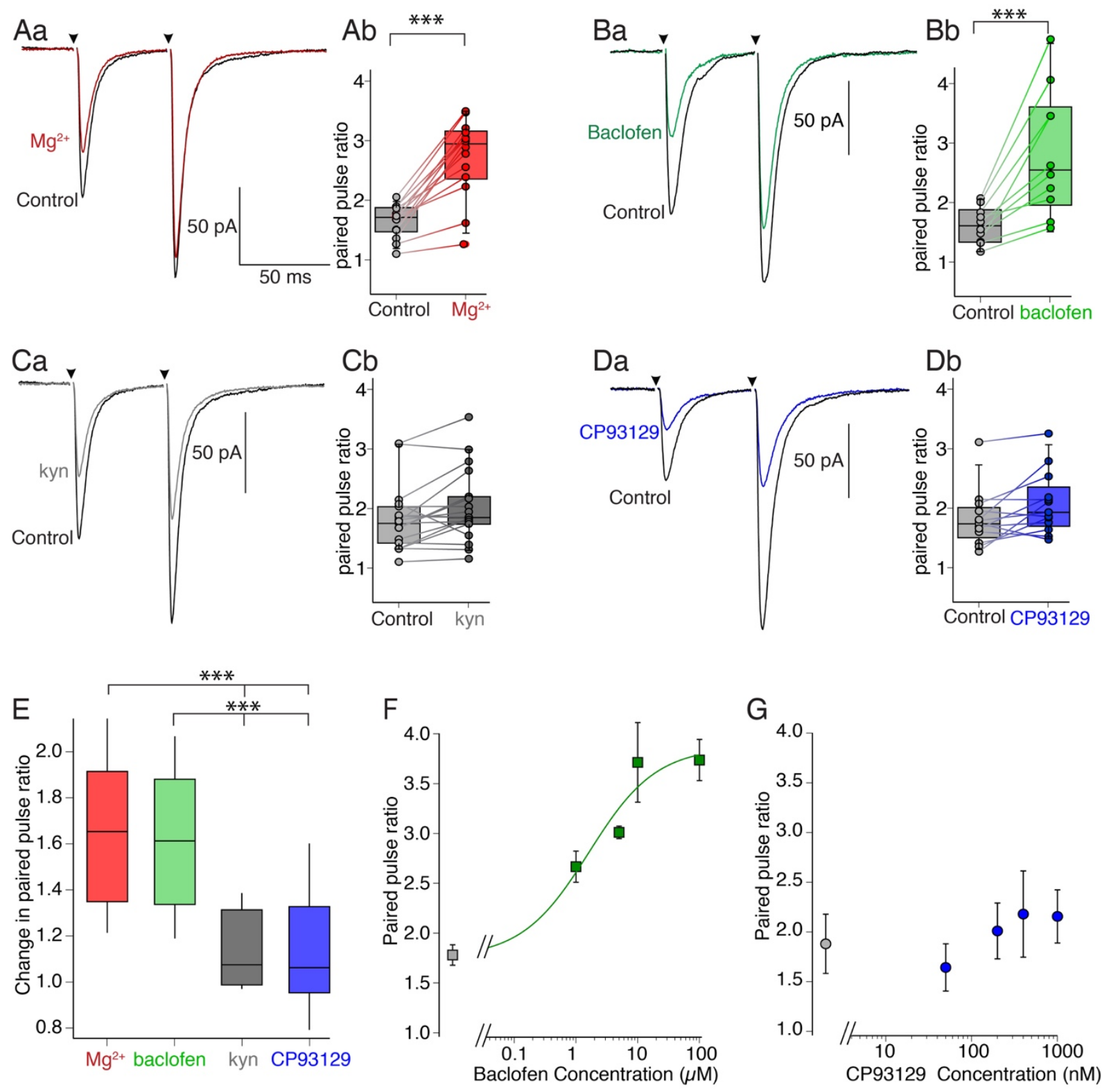

A) Paired pulse stimuli applied to CA1 axons (50ms intervals). (Aa) Means of 10 EPSCs.

Extracellular $\left[\mathrm{Mg}^{2+}\right]$ was raised from 1 to $4 \mathrm{mM}$ to reduce $\mathrm{Ca}^{2+}$ entry (red) and thus $\mathrm{P}_{\mathrm{r}}$. This reduced the mean amplitude of the first EPSC more than the second. The effect of high $\mathrm{Mg}^{2+}$ on the paired pulse ratio (PPR) is quantified to show scatter plots of PPRs in control and high $\mathrm{Mg}^{2+}$ for each cell and box plots of the same data $(A b)$. 
B) A similar experiment but with addition of the $\mathrm{GABA}_{B}$ receptor agonist, baclofen. (Ba, $\left.600 \mathrm{nM}\right)$, mean EPSCs show an increase in PPR quantified in $\mathrm{Bb}$ as for Ab.

C) A negative control using a glutamate receptor antagonist, kynurenate $(200 \mu \mathrm{M}$; grey). This gave no change in PPR (Ca, quantified in $\mathrm{Cb})$.

D) Similar experiment but with the 5- $\mathrm{HT}_{1 \mathrm{~B}}$ receptor agonist, CP93129 (50nM; blue). This again gave no change in PPR (Da, quantified in $\mathrm{Db})$.

E) Changes in PPRs normalized to pre-treatment controls shown as box plots $(1.0=$ no change, boxes 25 and $75 \%$ with means, whiskers to 10 and $90 \%$ ) for all recordings in the conditions shown in (A-D).

F) The effect of baclofen concentration vs. normalized PPR was plotted. This is concentration dependent.

G) The effect of CP93129 concentration on PPR was plotted. This was not concentrationdependent 
Figure 3. 5- $-\mathrm{HT}_{1 \mathrm{~B}}$ but not $\mathrm{GABA}_{B}$ receptors increase the potency of a low affinity AMPA receptor antagonist-mediated block of EPSCs
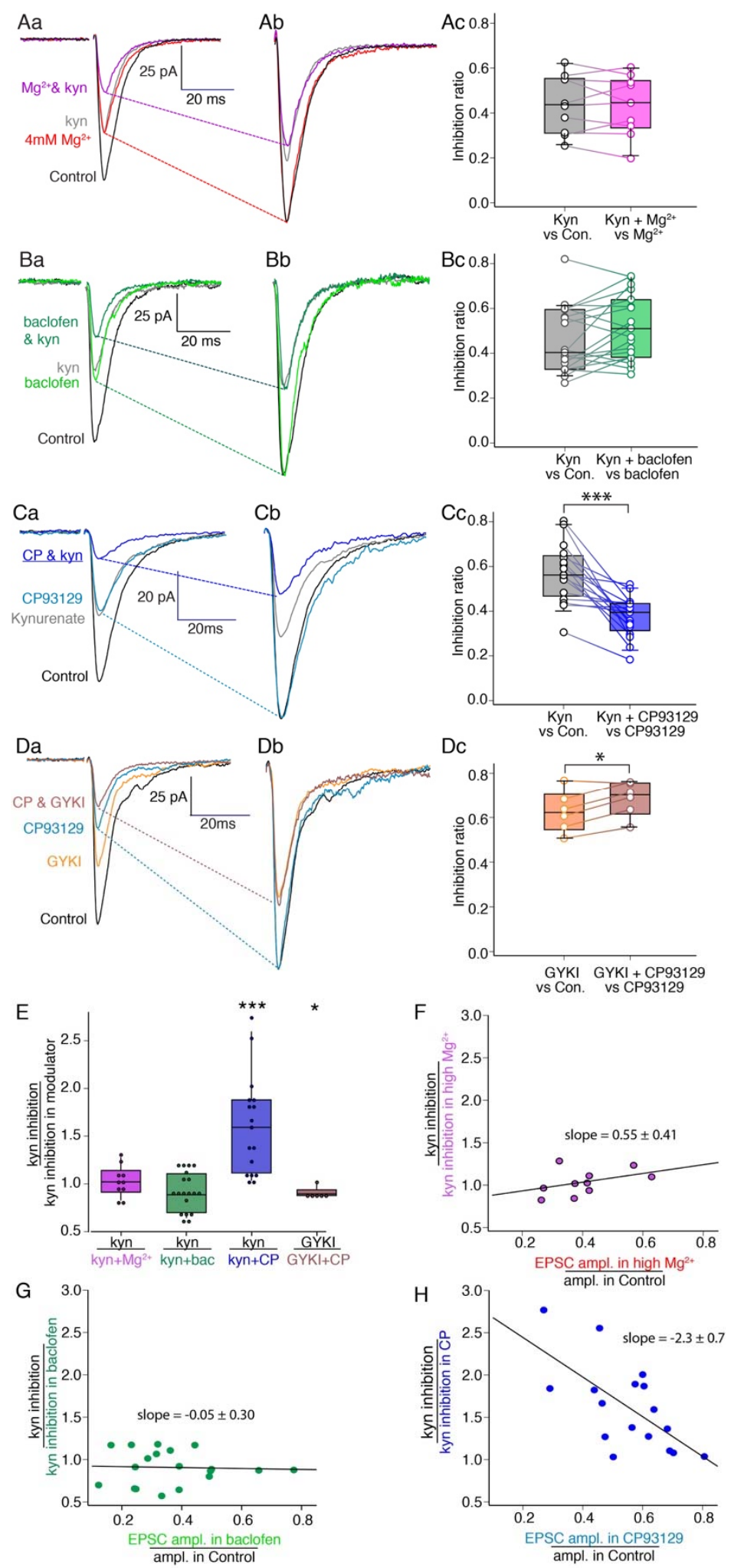
A) Effect of raised $\mathrm{Mg}^{2+}$ on EPSC inhibition by a low affinity competitive antagonist, kynurenate. (Aa) Kynurenate $(200 \mu \mathrm{M}$; gray) partially inhibited EPSCs, shown as means of 10 traces. After kynurenate wash, $4 \mathrm{mM} \mathrm{Mg}^{2+}$ (red), to decrease $\mathrm{P}_{\mathrm{r}}$ reduced EPSCs. Kynurenate $200 \mu \mathrm{M}$ was then combined with high $\left[\mathrm{Mg}^{2+}\right]$ (purple). (Ab) For clarity, traces in $4 \mathrm{mM} \mathrm{Mg}^{2+}$ scaled to control. (Ac) Kynurenate inhibited EPSCs to a similar ratio in control and $4 \mathrm{~mm} \mathrm{Mg}^{2+}$. Inhibition ratios plotted and overlaid on boxplots (boxes 25 and 75\% with means, whiskers to 10 and $90 \%$ ) Ba) Kynurenate $(200 \mu \mathrm{M}$; gray) reduced EPSCs. After kynurenate wash, baclofen (600 nM; light green) reduced the EPSC. Kynurenate $(200 \mu \mathrm{M})$ with baclofen $(600 \mathrm{nM}$; dark green) reduced the EPSC similarly to baclofen alone. $(\mathrm{Bb})$ Reponses in baclofen scaled as for $\mathrm{Ab} .(\mathrm{Bc})$ data from all cells.

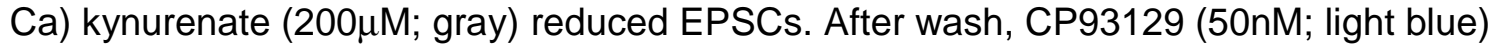
reduced the EPSC. Kynurenate $(200 \mu \mathrm{M})$ with 50nM CP93129 (blue) reduced the EPSC to a greater proportion than CP93129 alone. (Cb) Reponses in CP93129 scaled as for Ab. (Cc) data from all cells.

D) Non-competitive AMPA receptor antagonist GYKI used as control. (Da) GYKI (10 $\mu \mathrm{M}$; orange) reduced EPSCs. After wash, CP93129 (50nM) inhibited EPSCs (blue). Co-application of 10 $\mu \mathrm{M}$ GYKI with 50nM CP93129 (pink) reduced EPSCs as controls. (Db) Responses in CP93129 scaled as above. (Dc) data from all cells.

E) Box plots overlaid with individual cell data comparing ratio of inhibition by kynurenate or GYKI alone, to inhibition in kynurenate plus high $\mathrm{Mg}^{2+}$ (pink), baclofen (green) or CP93129 (blue) or to GYKI and CP93129 (brown). A value of 1 indicates the modulatory agonist had no effect on kynurenate or GYKI potency, higher values show enhanced potency. F) Change in kynurenate inhibition caused by $4 \mathrm{mM} \mathrm{Mg}^{2+}$ (data from A) plotted against initial efficacy of $4 \mathrm{mM} \mathrm{Mg}^{2+}$ for each neuron. The slope was indistinguishable from zero. 
G) Similar effect by baclofen on kynurenate inhibition (B) plotted against initial efficacy of baclofen in each neuron. Slope was again indistinguishable from zero.

H) Change in kynurenate inhibition by CP93129 (C) plotted against the initial efficacy of CP93129 in each neuron. Slope $(-2.3)$ showed correlation $\left(R^{2}=0.4\right)$. 
Figure 4. Stability of Recording Access
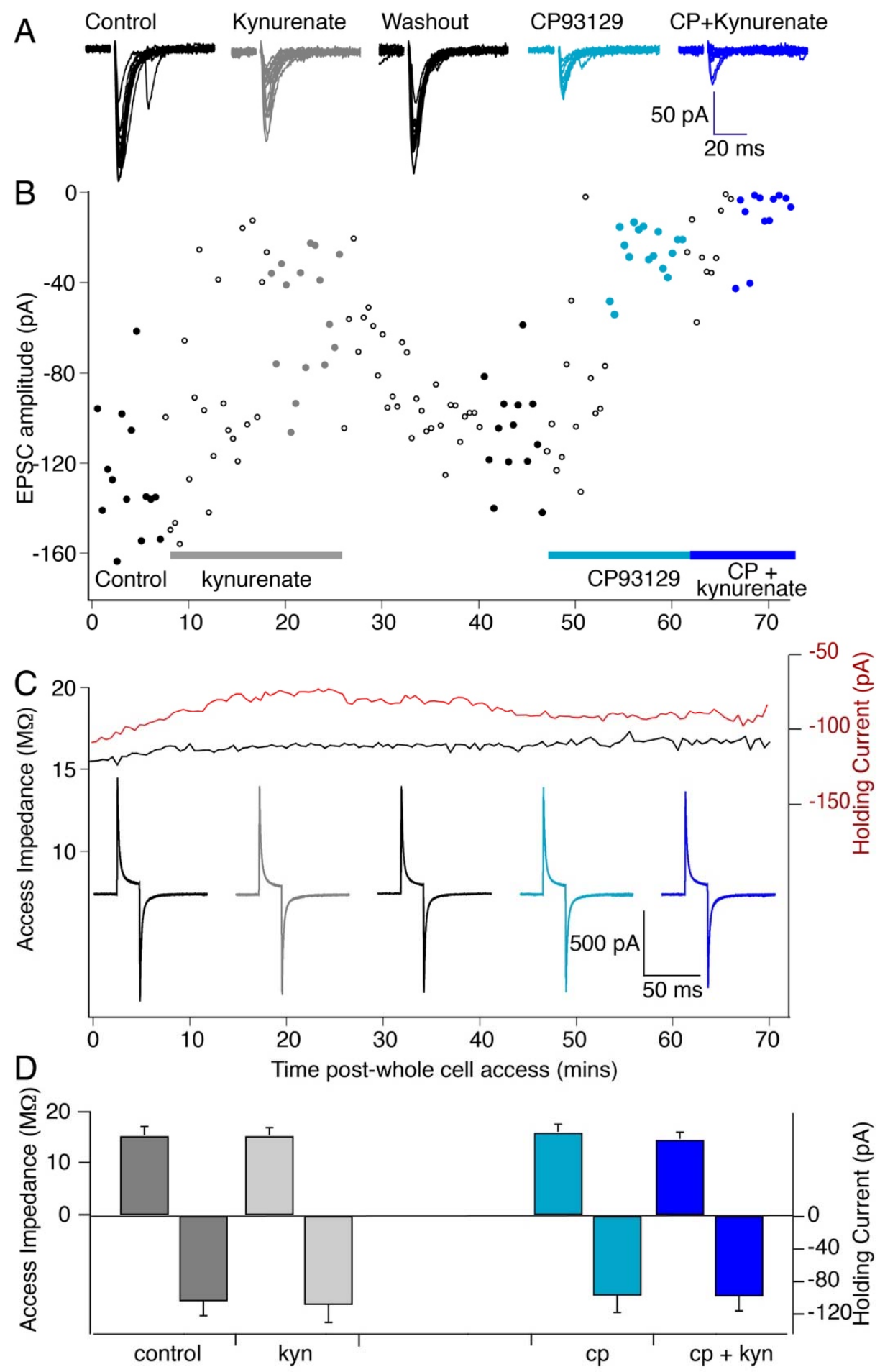

Ligand application 
A) Sequential recordings of evoked AMPA receptor-mediated EPSCs during recording through each drug condition to show recording stability. Individual EPSCs are shown for one recording in which the effects of CP93129 and its amplification by kynurenate were tested.

B) Graph of peak amplitudes of all EPSCs were recorded. Closed circles are measured responses corresponding to the EPSCs shown in (A). Open circles during washin in or washout of the drugs were not measured. Colors correspond to EPSCs in (A).

C) Graphs show whole cell access impedance (black) calculated, and holding current (red) throughout the experiment. Whole cell access impedances $\left(R_{a}\right)$ were calculated from double exponentials fit to the decays from small depolarizing current steps applied before each EPSC was stimulated (Sigworth, 1983). Example responses to voltage steps at each drug application are shown. Color as as for $(A)$.

D) From all cells, histograms show means \pm sem for access impedance (positive bars) and holding currents (negative bars) during control, application of kynurenate, of CP93129 and kynurenate+CP93129. Colors during ligand applications are the same throughout the figure. 
Figure 5. Differential inhibition of AMPA and NMDA receptor mediated EPSCs

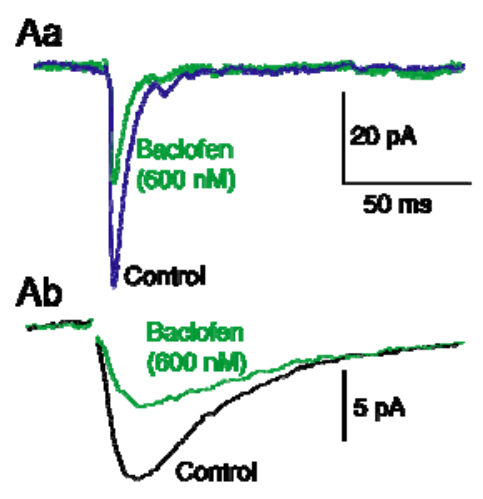

$\mathrm{Ba}$
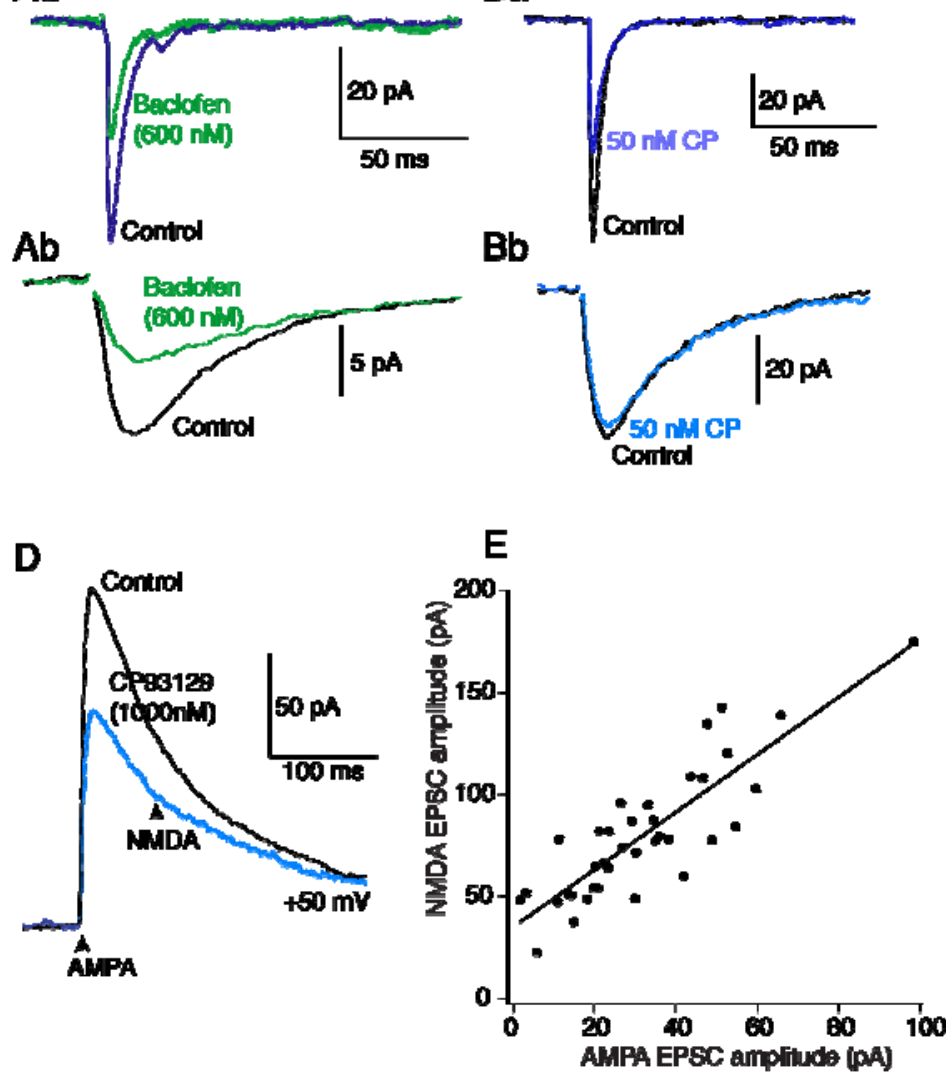
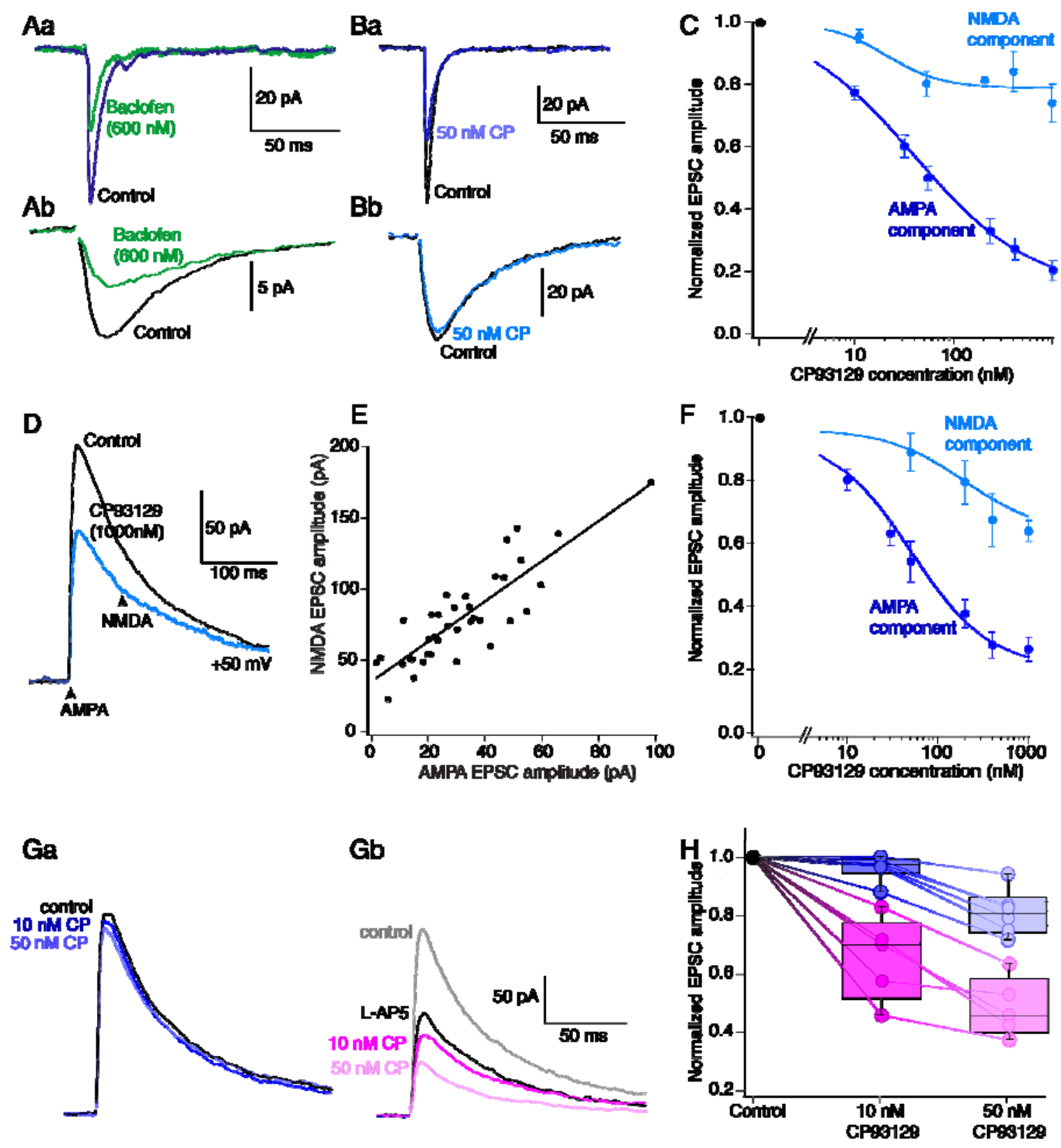

A) In separate recordings AMPA mediated EPSCs were recorded in D-AP5 (Aa) and NMDAmediated EPSCs in NBQX (Ab). Baclofen (600 nM; green) similarly inhibited both of these responses.

B) Similar recordings were made but CP93129 (Ba, $50 \mathrm{nM}$; blue) inhibited the AMPA receptor mediated EPSC, but not the NMDA receptor mediated EPSC (Bb, red). 
C) Concentration response effects of CP93129 vs the AMPA (blue) and NMDA receptor EPSCs (red) show a large difference in efficacy.

D) The differential effect of CP93129 on AMPA and NMDA receptor responses are found at the same synapses. Compound EPSCs without glutamate receptor antagonists recorded at a holding potential of $+50 \mathrm{mV}$. Early responses ( $2 \mathrm{~ms}$ post stimulus) are dominated by AMPA receptors (bottom arrow), late responses (100 ms post stimulus) by NMDA receptors. CP93129 at a saturating dose $(1 \mu \mathrm{M})$ was applied (red).

E) For individual recordings, sequential response amplitudes of AMPA and NMDA responses were plotted against each other. These responses covaried indicating they colocalise to the same synapses.

F) Mean amplitudes of AMPA and NMDA receptor mediated EPSCs during the same stimuli plotted with increasing concentrations of CP93129. AMPA receptor EPSCs were inhibited to a greater extent than were NMDA receptor EPSCs.

G) CP93129 mediated inhibition of the NMDA component is amplified by the low affinity competitive antagonist (L-AP5). In control experiments (Ga) 10 and 50 nM CP93129 (blue) had little effect on isolated NMDA mediated EPSC (recorded at $+50 \mathrm{mV}$ in NBQX and bicuculline). LAP5 $(250 \mu \mathrm{M})$ partially inhibited this response (Eb, black). This inhibited response was now substantially inhibited by 10 and 50 nM CP94129.

H) Quantitation of the data from (G) showing inhibition by CP93129 in control (blue, normalized to precontrol recordings) and after treatment with L-AP5 (pink, normalized to recordings in LAP5 alone. 
Figure 6. Imaging evoked glutamate release with iGluSnFR
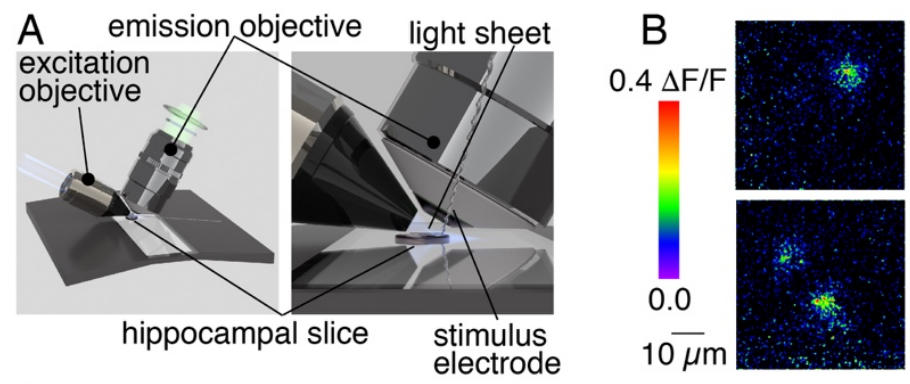

C Control
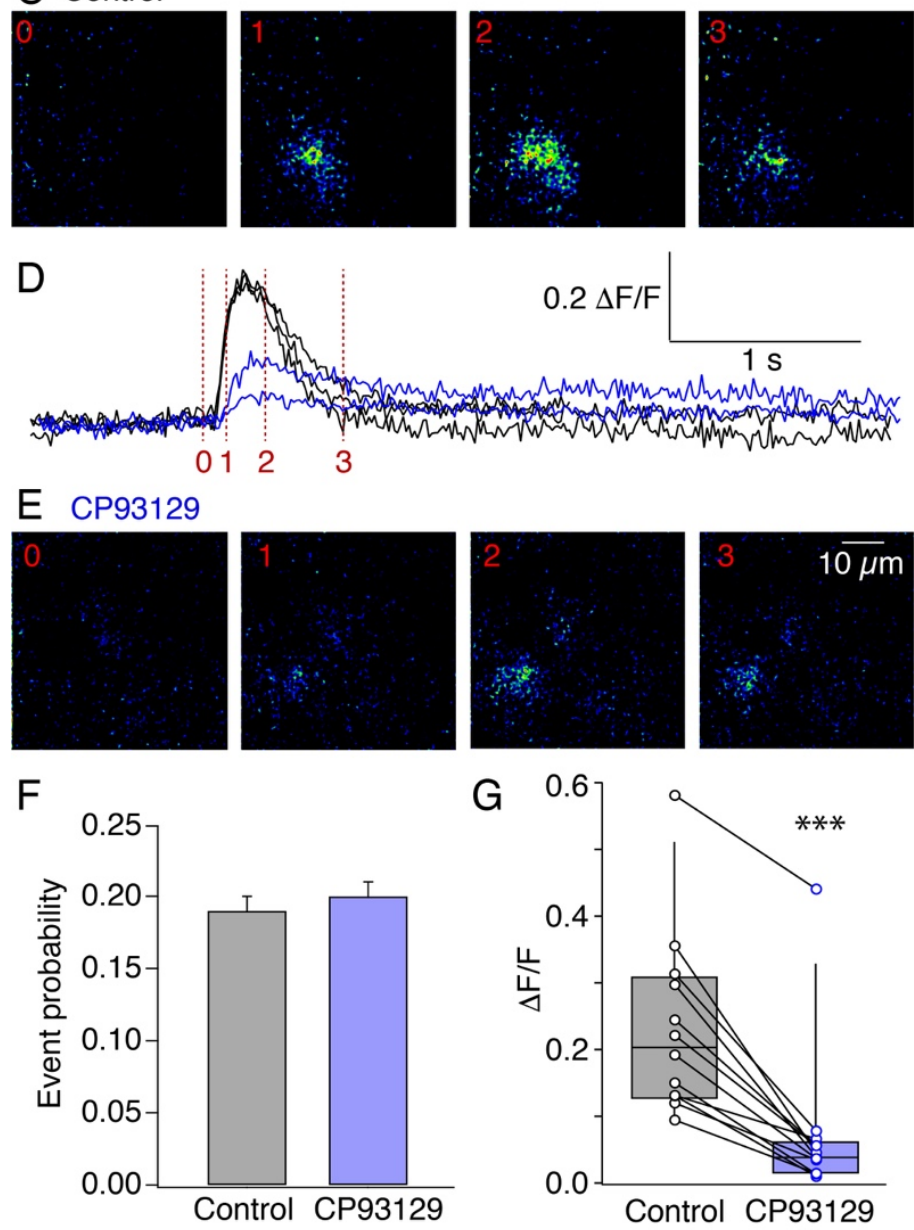

A) Imaging of iGluSnFR expressed in subicular neurons was perform under LLSM adapted to allow recording and stimulation of hippocampal slices. The schematic shows the arrangement of preparation and lenses.

B) While imaging labeled subicular pyramidal neurons dendrites, repeated stimulation (1 shock at $5 \mathrm{~s}$ intervals) caused stochastic fluorescent transients in subiculum. Shown are 3 responses from 2 separate stimuli. 
C) Evoked transients recorded in one z plane at $80 \mathrm{~Hz}$ expanded from a spot to larger diameter (5 - $10 \mu \mathrm{m}$ diameter) objects (time point noted in $\mathrm{D}$, red).

D) Transient amplitudes and timecourses were calculated from a $5 \mu \mathrm{m}$ diameter ROI over the transients. Three responses at the same location were obtained from 14 stimuli. Application of CP93129 (100 nM) reduced the amplitude of the transients. Two responses were recorded in 14 stimuli.

E). Evoked transients recorded in one z plane in CP93129 (100 nM).

F) CP93129 caused no change in the probability of recording events at the same location over 21 stimuli.

Box plot with overlaid individual transient data showing the CP93129 reduced the amplitudes of transients. 
Figure 7. Simulating neurotransmitter release and receptor activation

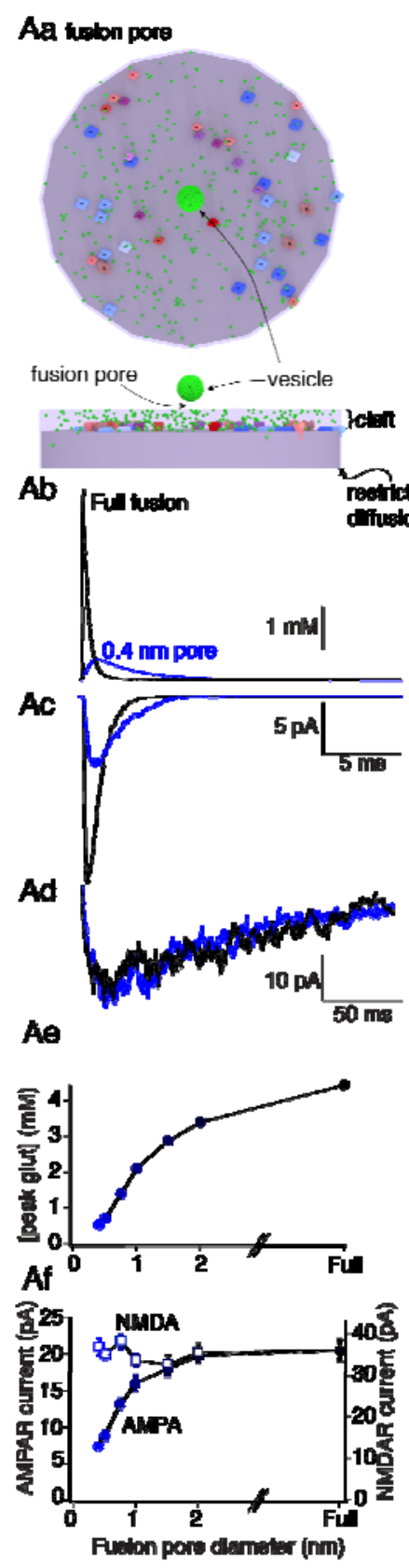

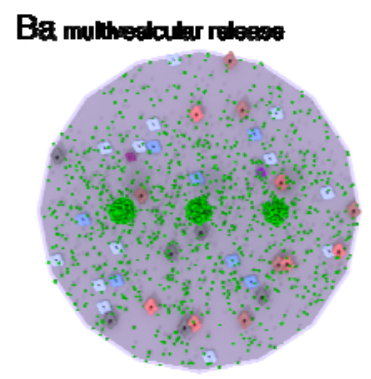

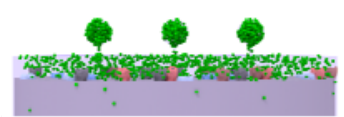

$\mathrm{Bb}$
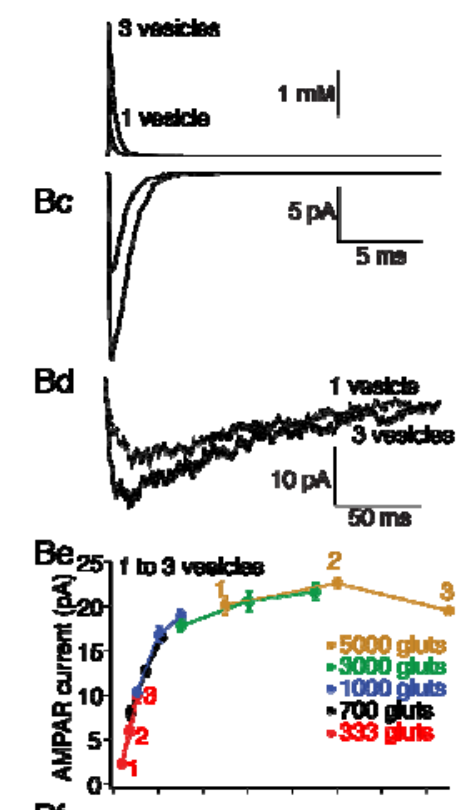

\section{Bf}

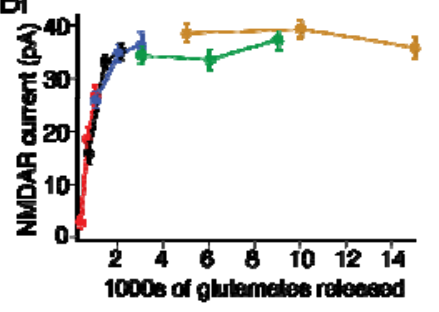

Ca vedcle bcatton vaulos
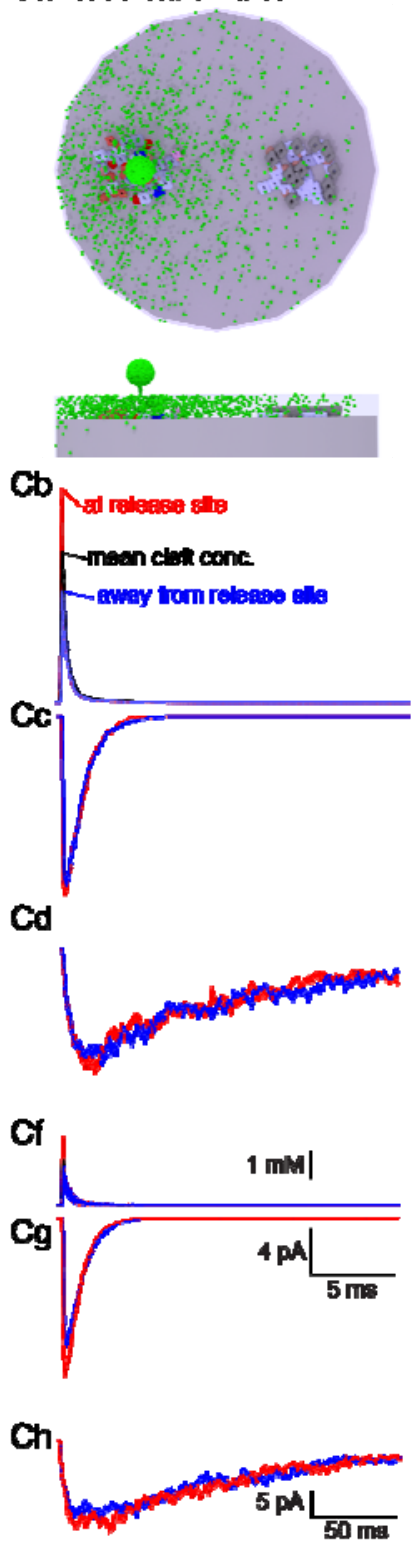
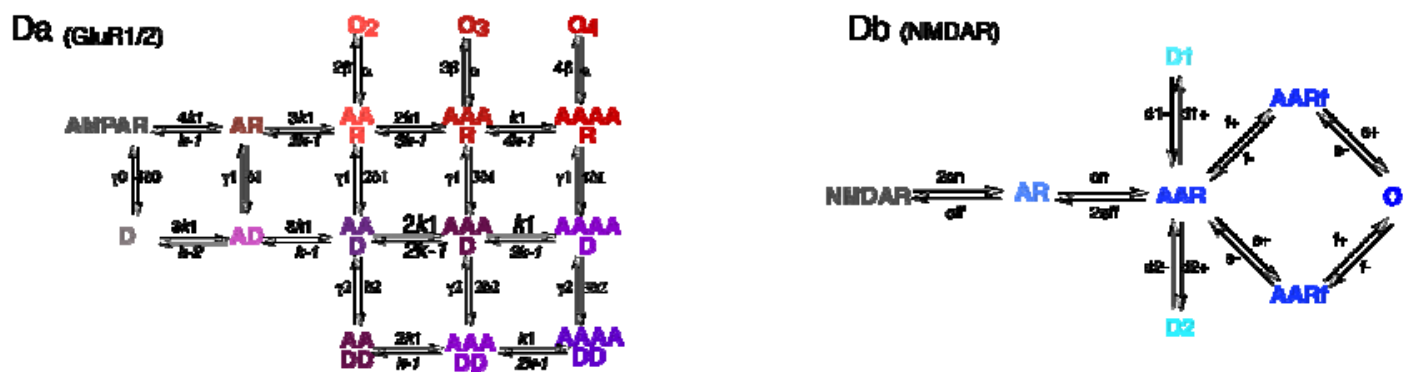
Aa) Simulated $300 \mathrm{~nm}$ diameter synapses, $20 \mathrm{~nm}$ deep synaptic clefts and a $1 \mathrm{~nm}$ path at the edge to restrict fusion. Image is from $500 \mu$ s after the start of fusion. To simulate a fusion pore, fusion started from a pore at fixed diameter $(0.4 \mathrm{~nm}$ for $20 \mathrm{~ms})$ before fully opening (Aa) or pores that fully opened within $200 \mu \mathrm{s}$. Simulated receptors were randomly seeded on the postsynaptic surface (receptor colors as for kinetic models (D).

Ab) Varying initial fixed pore diameters slowed glutamate release, reduced its cleft concentration (graphed $\mathrm{Ae}$ ) and differentially inhibited AMPA (Ac) over NMDA (Ad) receptormediated responses (graphed Af, AMPA filled circles, NMDA hollow squares).

Ba) Simulated multivesicular release pattern. 3 simulated vesicles where vesicle number was varied from 3 to 1 with 333 to 5000 glutamates/vesicle.

$\mathrm{Bb})$ The effect on cleft glutamate concentration of reducing vesicle numbers from 3 to 1 when each contained 700 glutamates. The AMPA receptor response $(\mathrm{Bc})$ and the NMDA receptor response $(\mathrm{Bd})$ are shown below. Graphs show the AMPA $(\mathrm{Be})$ and the NMDA receptor responses (Bf). To each condition, both varying glutamates/vesicle (color coded) and number of vesicles, each point in the colored sections.

Ca) The effect of varying the position of the release site with respect to postsynaptic clustered receptors was simulated. Two receptor clusters were seeded with a mean separation of $150 \mathrm{~nm}$ and the releasing vesicle positioned over one.

$\mathrm{Cb}$ ) cleft glutamate concentrations over the clusters (red at release site, blue away from release) and mean cleft concentration (black) after 5000 glutamates were released in $200 \mu \mathrm{s}$. Cc) AMPA receptor responses simulated under the release site (red) and away from the site (blue). Cd) NMDA receptor responses.

Cf-h) Similar experiment to $\mathrm{Cb}-\mathrm{d}$, but with 1500 glutamate molecules to reveal modulation of AMPA and NMDA receptor mediated responses.

Da) Kinetic model for AMPA and (Db) for NMDA receptors (parameters in table 1). Colors are the same as shown for receptors in $\mathrm{Aa}, \mathrm{Ba}$ and $\mathrm{Ca}$. 
bioRxiv preprint doi: https://doi.org/10.1101/2020.11.12.362491; this version posted June 25, 2021. The copyright holder for this preprint (which was not certified by peer review) is the author/funder, who has granted bioRxiv a license to display the preprint in perpetuity. It is made available under aCC-BY-NC-ND 4.0 International license.

Fig 8. Simulating cleft glutamate modulation and kynurenate inhibition

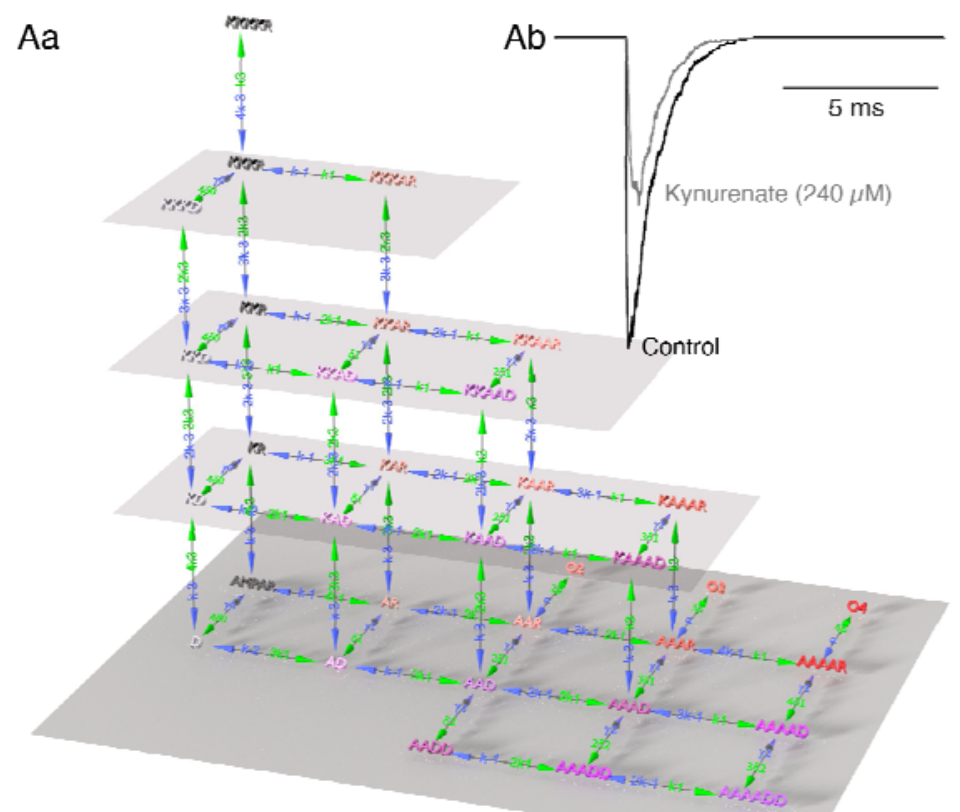

$\mathrm{Ba}$

$\mathrm{Bb}$

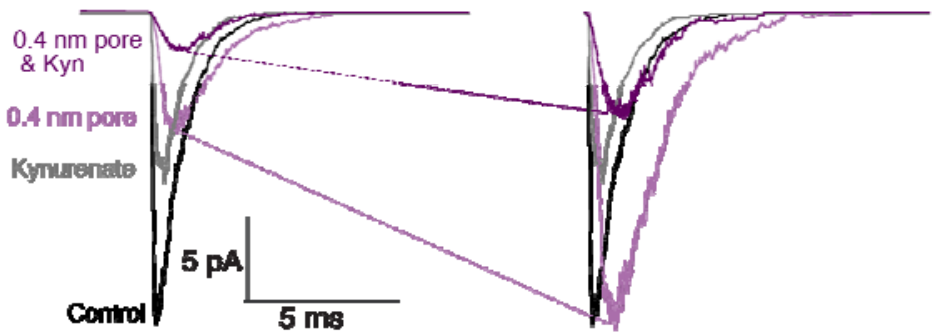

$\mathrm{Ca} \quad \mathrm{Cb}$
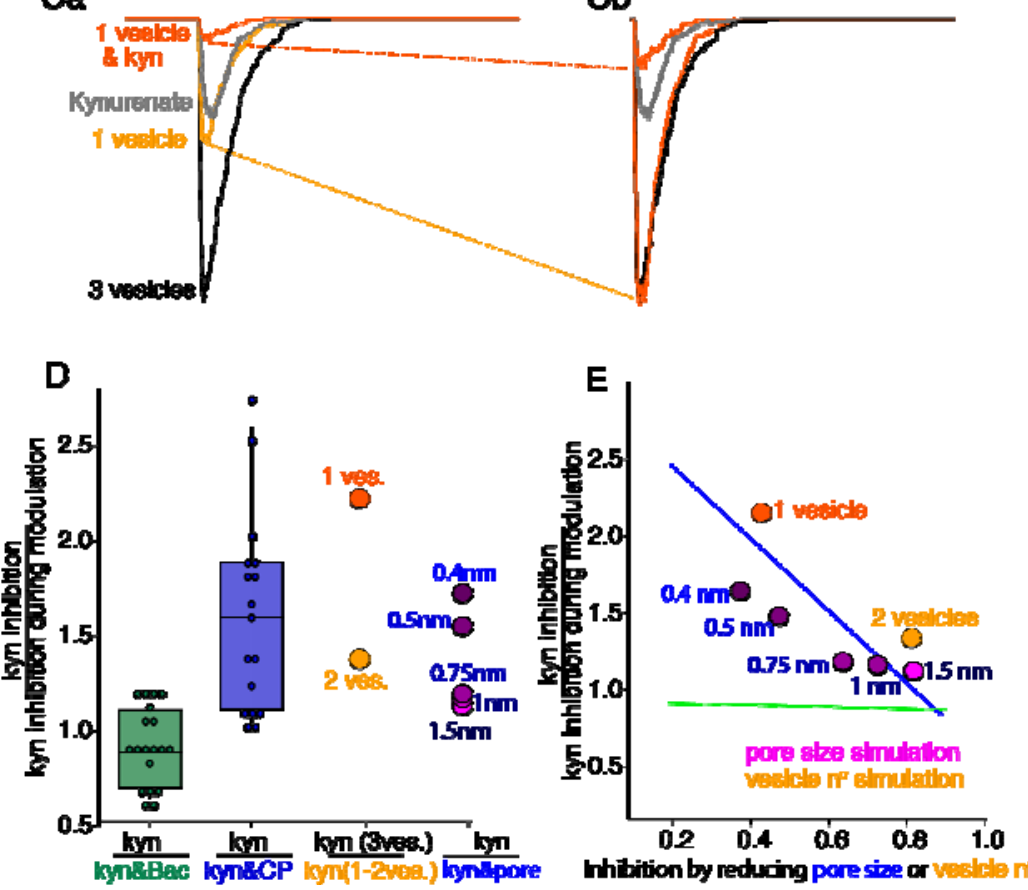
Aa) Kinetic model of AMPA receptor activation by glutamate and block by kynurenate. (Colors and lowest tier of 3D model are as for Fig 6Da, Vertical elements of the 3D representation show kynurenate occupying receptor bound and desensitized states, parameters in table1). Ab) Simulated full fusion in $200 \mu$ s with 5000 glutamates (black, control) and the effect of $240 \mu \mathrm{M}$ kynurenate (gray).

$\mathrm{Ba})$ The effect of kynurenate (gray) on control simulated responses (black) and on the response when the vesicle fusion pore was restricted to $0.4 \mathrm{~nm}$ (light purple without, purple with kynurenate). $\mathrm{Bb}$ ) Full fusion responses and $0.4 \mathrm{~nm}$ pore responses scaled to emphasize effect of kynurenate is amplified by the $0.4 \mathrm{~nm}$ pore.

Ca) Simulation as numbers of vesicle were varied from 3 to 1, each with 700 glutamates as in Fig 6Bb-d. Effect of kynurenate (gray) on 3 vesicle response (black), and on 1 vesicle response (light orange) plus kynurenate (orange). $\mathrm{Cb}$ ) Responses scaled for to compare effect of kynurate on the 3 vesicle and 1 vesicle responses.

D) Comparison of magnification of kynurenate inhibition by baclofen (green) and CP93129 (blue) from experimental data (Fig 3E) to the effect on kynurenate inhibition in simulations of reducing vesicle numbers (orange) or changing the initial fixed vesicle pore diameter (purple). E) Simulation data (from D) plotted against the effect of reducing vesicle number (orange) or fusion pore size (purple) on AMPA receptor responses. The green line is the fit to the similar effect of kynurenate on variations in experimental baclofen inhibition (from Fig 3G). The blue line similarly for experimental CP93129 variation (from Fig 3H). 
Fig 9. Effect of agonist of AMPA-mediated EPSC kinetics
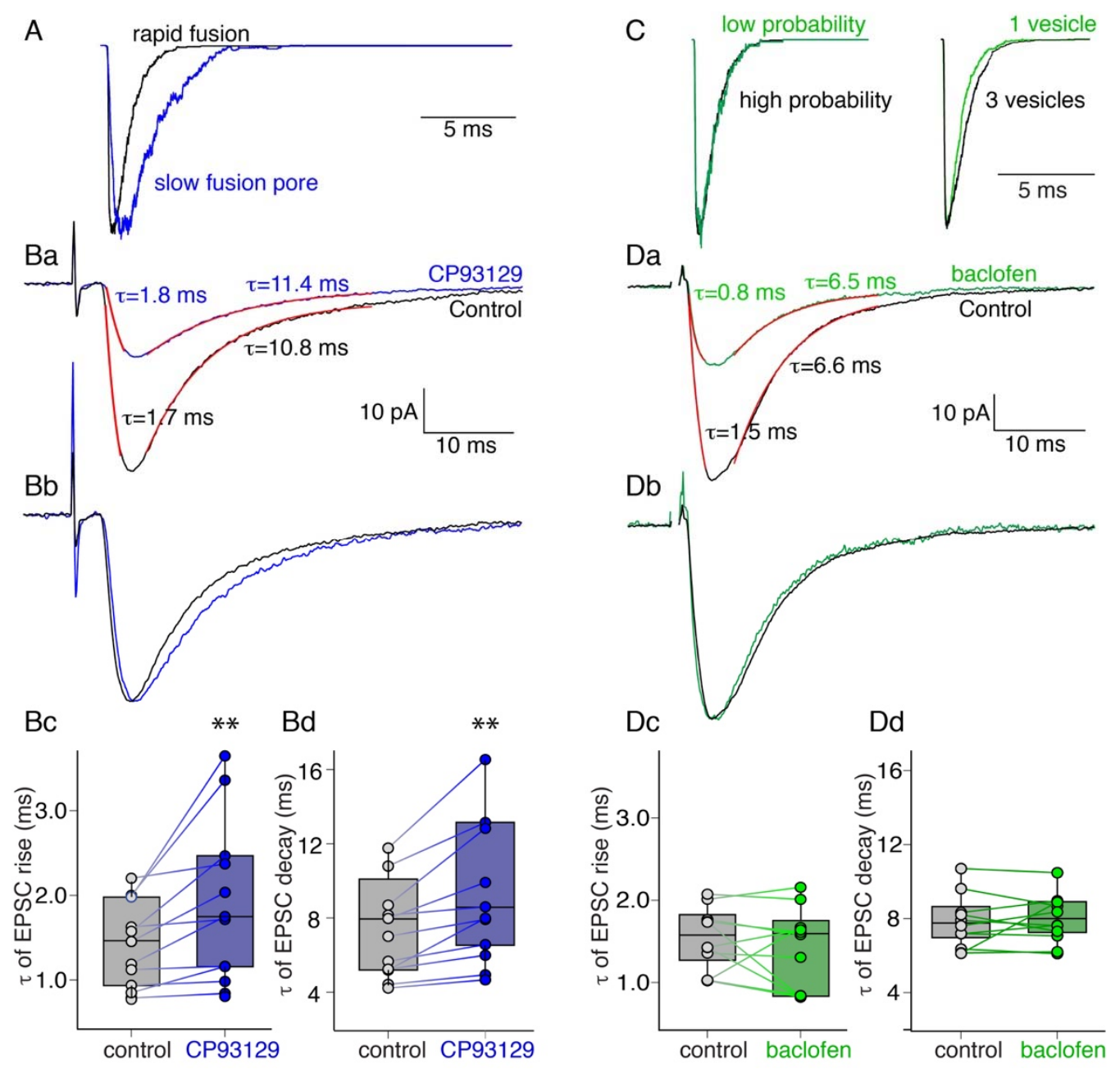

A) Data from simulating full fusion and a $0.4 \mathrm{~nm}$ pore scaled to the same amplitude to show the slowing of the rise and decay times of the resultant AMPA receptor-mediated response.

Ba) Experimental data of control responses (mean of 10 sequential EPSCs, black) and responses in the same neuron in CP93129 (50 nM, blue). Red curves are single exponentials fitted to 10 to $90 \%$ of the rise and of the decay phases. $\mathrm{Bb}$ ) response amplitudes scaled to emphasize the change in rates of the response in CP93129. Bc) Box plots and data points for the risetime in control (gray) and in CP93129 (blue), Bd) for decay times. 
C) Simulated AMPA mediated EPSCs scaled to show the kinetic effect of reduced number of responses to mimick a change of $\mathrm{P}_{\mathrm{r}}$ at univesicular synapses on simulated kinetics (right) or reduced number of vesicles (from 3 to 1) at multivesicular synapses (left).

Da) Experimental control responses (black) and in the same neuron in baclofen (600 nM, green). Red curves show single exponentials fitted to rise and decay phases as in $\mathrm{B}$. Db)

Response amplitudes scaled as in B. Dc) Box plots and data points for the risetime in control (gray) and in baclofen (green), Dd) similarly for decay times. 
Figure 10. Effect of repetitive stimulation on inhibition
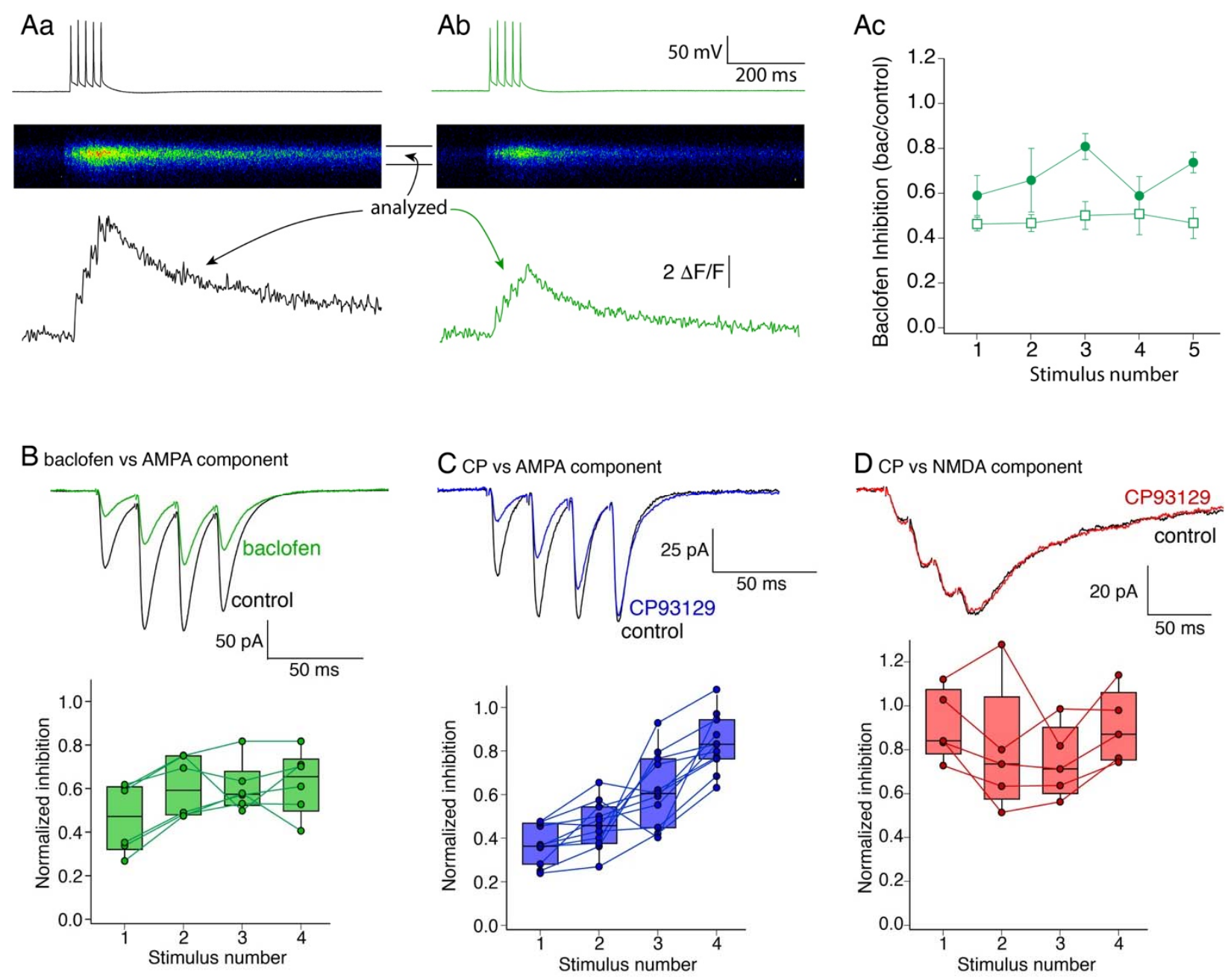

A) Line scans through single CA1 neuron presynaptic varicosities imaged from neurons filled with $\mathrm{Ca}^{2+}$ dye (Fluo5F) from whole cell patch recordings. Aa) A train of 5 action potentials (top) were triggered via the patch pipette to evoke a train of fluorescence transients in the varicosity (middle) that were quantified (bottom). Ab) Baclofen (600nM) did not prevent evoked events but reduced the differential amplitude of each event in the train (Ac, closed circles) and the summation of the response measured as the reduction of absolute amplitude following each action potential (Ac, open squares).

B) Train of stimuli (4 shocks, $50 \mathrm{~Hz}$ ) applied to CA1 axons to evoke AMPA EPSCs recorded in subicular neurons (in D-AP5 and bicuculline at a holding potential of -60mV). CP93129 (400nM, 
blue) markedly inhibited the first response in the train, but the EPSCs recovered to control amplitudes by the fourth stimulus. Example is of mean response from 10 sequential trains. Box plots and single data show effects in 9 neurons of CP93129 (400nM on amplitudes of responses from each of the 4 stimuli in the train.

C) A similar train stimulus applied in a preparation superfused with NBQX and bicuculline to isolate the NMDA receptor EPSCs. EPSCs were recorded at $-35 \mathrm{mV}$ to eliminate $\mathrm{Mg}^{2+}$ block of the NMDA receptor. CP93129 (400nM) had little effect on any of the responses in the stimulus train. Box plots and raw data as for $\mathrm{A}$.

D) A similar train stimulus applied for isolated AMPA receptor mediated EPSCs in which Baclofen $(1 \mu \mathrm{M})$ inhibited EPSCs throughout the train of stimuli. Box plots and raw data as for $\mathrm{A}$. 
Figure 11. 5-HT $1 \mathrm{~B}$ receptors filter synaptic output of the hippocampus but these filter properties are modified by $\mathrm{GABA}_{B}$ receptors.
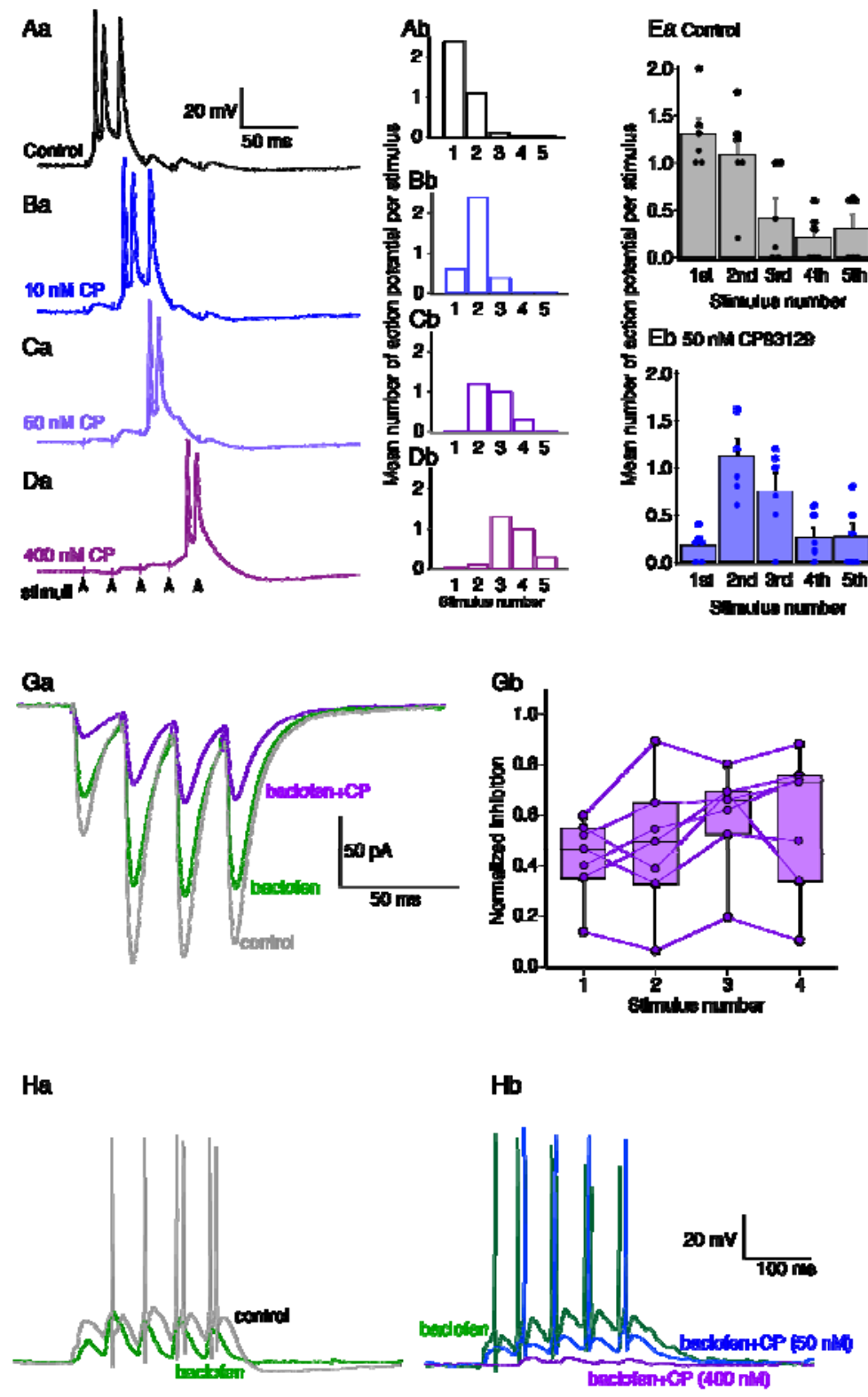

$\mathbf{F}$
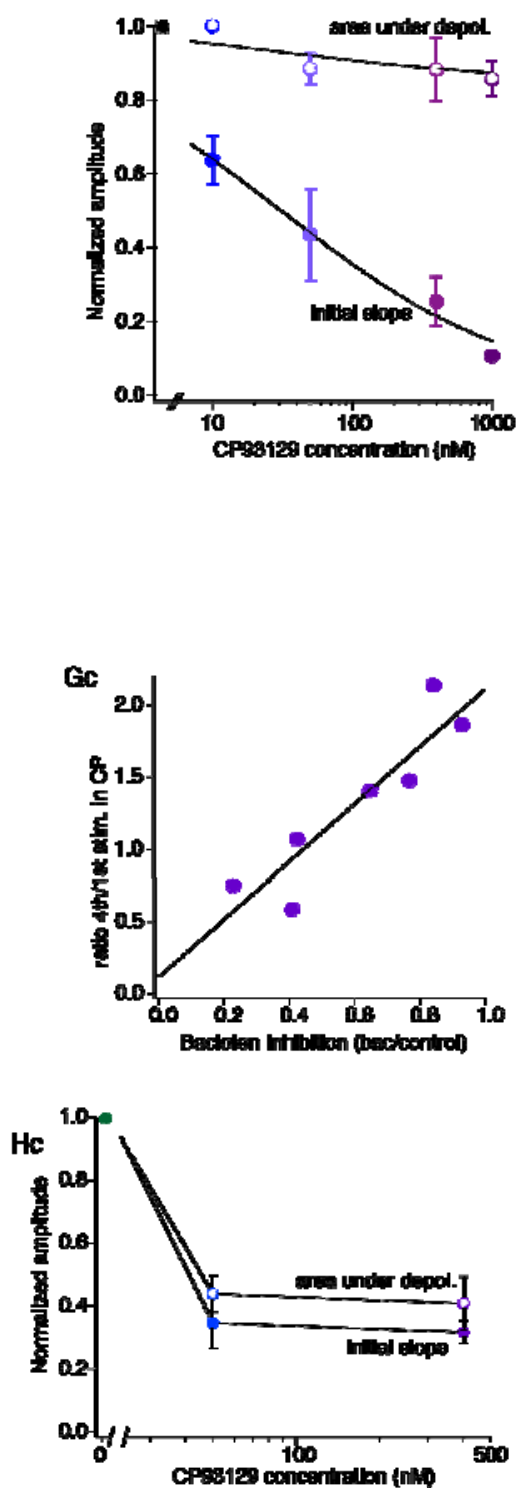

A) $5-\mathrm{HT}_{1 \mathrm{~B}}$ receptors suppress activity at the start of a train but not total activity. A stimulus train (5 shocks, $50 \mathrm{~Hz}$ ) was applied to CA1 axons, EPSPs recorded from subicular neurons. Stimulus intensity was adjusted to ensure the first train stimulus caused an AP. (Aa) Example control trace. (Aa) Histogram shows mean number of APs following each stimulus from 10 sequential trains from this cell. 
(Ba-Da) Recordings of the cell in (A) after in increasing concentrations of CP3129 (CP). (Bb-Db) AP counts from each stimulus in the recordings.

E) Mean APs counts from each stimulus from 4 cells. (Ea) in control and (Eb) in 50nM CP93129.

F) CP93129 inhibits the first EPSP but not the total excitation during a train. From 4 cells a comparison of dose dependence of CP93129 inhibition of the mean EPSP initial slope on stimulus 1 and mean area under the depolarization for all stimuli (data normalized to control response.

G) $\mathrm{GABA}_{\mathrm{B}}$ receptor activation modifies the filtering effect of $5-\mathrm{HT}_{1 \mathrm{~B}}$ receptors. $\mathrm{Ga}$ ) As shown in Fig 9, baclofen (green) $1 \mu \mathrm{M}$ inhibits EPSPs uniformly throughout the stimulus train. CP93129 (400 nM purple) in the presence of baclofen now also inhibits uniformly throughout the train. Examples are mean responses from 10 sequential trains in one cell. Gb) Box plots and single data show effects in 7 neurons of adding CP93129 (400nM) to baclofen on responses from each of the 4 stimuli in the train. Gc) the effect of CP93129 on the last EPSC in the train is proportional to the initial inhibtory effect of baclofen.

Ha) The modulating effect of Baclofen $1 \mu \mathrm{M}$ on CP93129 inhibition is seen in current clamp recordings. Baclofen (green) inhibited EPSPs throughout the train. $\mathrm{Hb}$ ) In the same recording in baclofen the stimulation intensity was increased (green). CP93129 was added at $50 \mathrm{nM}$ (light blue) and $400 \mathrm{nM}$ (dark blue). EPSPs in baclofen were now uniformly inhibited throughout the stimulus train. Hc) graph of amplitudes normalized to response in $1 \mu \mathrm{M}$ baclofen for the first EPSP in the train and for the total area under the depolarization in increasing CP3129 concentrations. 
Table 1 Monte Carlo Simulation Parameters and Sources

\begin{tabular}{|c|c|c|}
\hline Parameter & value & source \\
\hline $\begin{array}{l}\text { Glutamate diffusion constant } \\
\left(\mathrm{cm}^{2} \cdot \mathrm{s}^{-1}\right)\end{array}$ & $3 \times 10^{-6}$ & $\begin{array}{l}\text { (Rusakov and Kullmann, } \\
\text { 1998) }\end{array}$ \\
\hline \multicolumn{3}{|l|}{$\begin{array}{l}\text { AMPA receptor parameters } \\
\text { (glutamate) }\end{array}$} \\
\hline $\begin{array}{l}\mathrm{k} 1\left(\mathrm{M}^{-1} \cdot \mathrm{s}^{-1}\right), \mathrm{k}-1\left(\mathrm{~s}^{-1}\right) \\
\mathrm{k}-2\left(\mathrm{~s}^{-1}\right) \\
\gamma_{0}, \delta_{0}\left(\mathrm{~s}^{-1}\right) \\
\gamma_{1}, \delta_{1}\left(\mathrm{~s}^{-1}\right) \\
\gamma_{2}, \delta_{2}\left(\mathrm{~s}^{-1}\right) \\
\beta, \alpha\left(\mathrm{s}^{-1}\right)\end{array}$ & $\begin{array}{l}2 \times 10^{7}, 9 \times 10^{3} \\
0.41 \\
1,3 \times 10^{-3} \\
7.6,1.8 \times 10^{3} \\
35,200 \\
8 \times 10^{3}, 3.1 \times 10^{3}\end{array}$ & (Robert and Howe, 2003) \\
\hline \multicolumn{3}{|l|}{ (kynurenate) } \\
\hline $\begin{array}{l}\mathrm{k} 3\left(\mathrm{M}^{-1} \cdot \mathrm{s}^{-1}\right) \\
\mathrm{k}-3\left(\mathrm{~s}^{-1}\right)\end{array}$ & $\begin{array}{l}5 \times 10^{7} \\
9000\end{array}$ & (Diamond and Jahr, 1997) \\
\hline \multicolumn{3}{|l|}{ NMDA receptor parameters } \\
\hline $\begin{array}{l}\text { on, off } \\
d_{1+}, d_{1-} \\
d_{2+}, d_{2-} \\
f_{+}, f_{-} \\
S_{+}, S_{-}\end{array}$ & $\begin{array}{l}95 \times 10^{5}, 29 \\
0.5,45 \\
70,2.8 \\
1557,182 \\
89, \quad 135\end{array}$ & (Banke and Traynelis, 2003) \\
\hline \multicolumn{3}{|l|}{ Mesh properties } \\
\hline $\begin{array}{l}\text { Internal vesicle diameter }(\mathrm{nm}) \\
\text { Pore length }(\mathrm{nm}) \\
\text { Minumum pore diameter }(\mathrm{nm}) \\
\text { Synaptic cleft thickness }(\mathrm{nm}) \\
\\
\text { Synaptic cleft diameter ( } \mathrm{nm}) \\
\text { Thickness of cleft edge diffusion } \\
\text { barrier (nm) }\end{array}$ & $\begin{array}{l}25 \\
8 \\
0.4 \\
20 \\
\\
300 \\
1.7\end{array}$ & $\begin{array}{l}\text { (Hu et al., 2008) } \\
\text { (Vardjan et al., 2007) } \\
\text { (Savtchenko and Rusakov, } \\
\text { 2007) } \\
\text { (Nimchinsky et al., 2002) } \\
\text { (Rusakov and Kullmann, } \\
\text { 1998) }\end{array}$ \\
\hline
\end{tabular}




\section{Multi}

medi

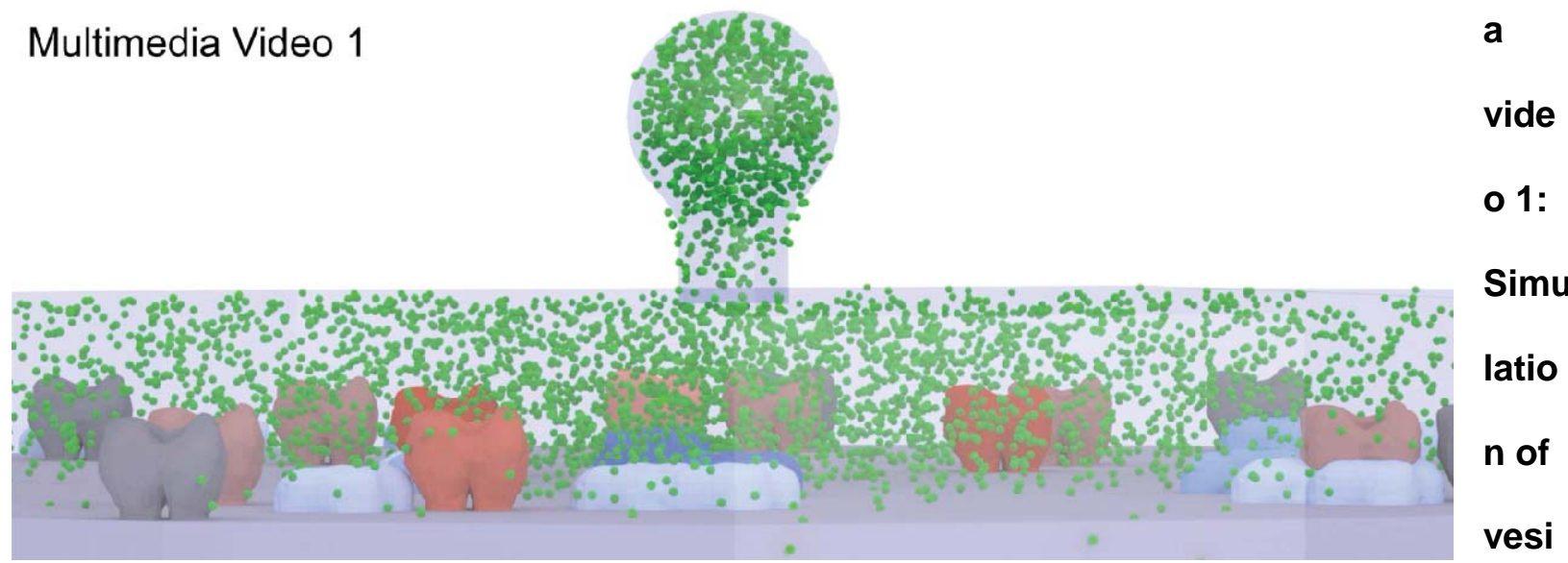

cle pore opening an expansion. This video shows the simulated synapse from the side demonstrating fusion of the vesicle compartment with the synaptic cleft, release of glutamate molecules (green) and binding of glutamate to post synaptic AMPA receptors (red shades) and NMDA receptors (blue shades). Receptor colors depend on kinetic state (see Fig 7D for kinetic models and colors). 


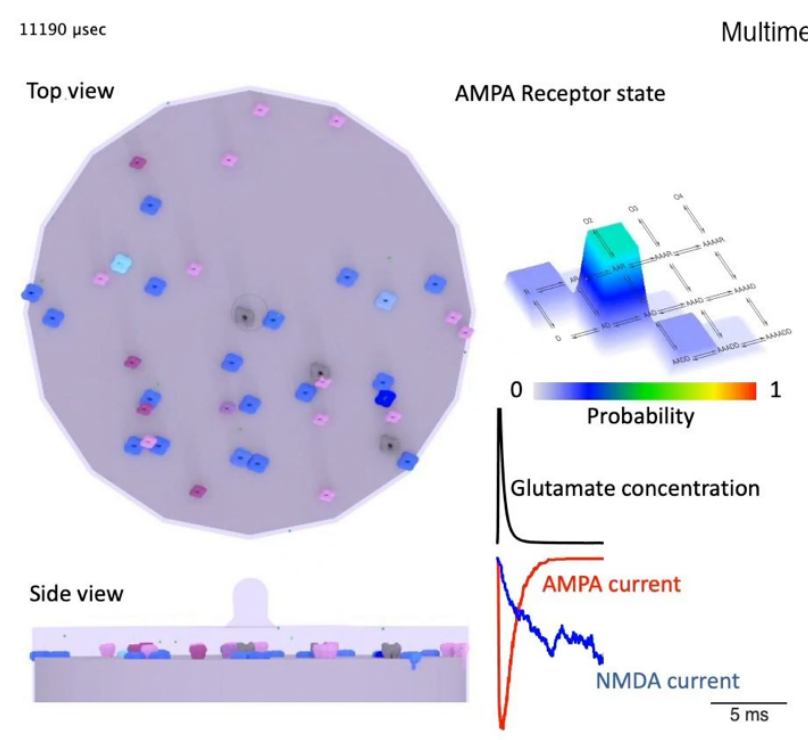

Full collapse fusion
Multimedia Video 2

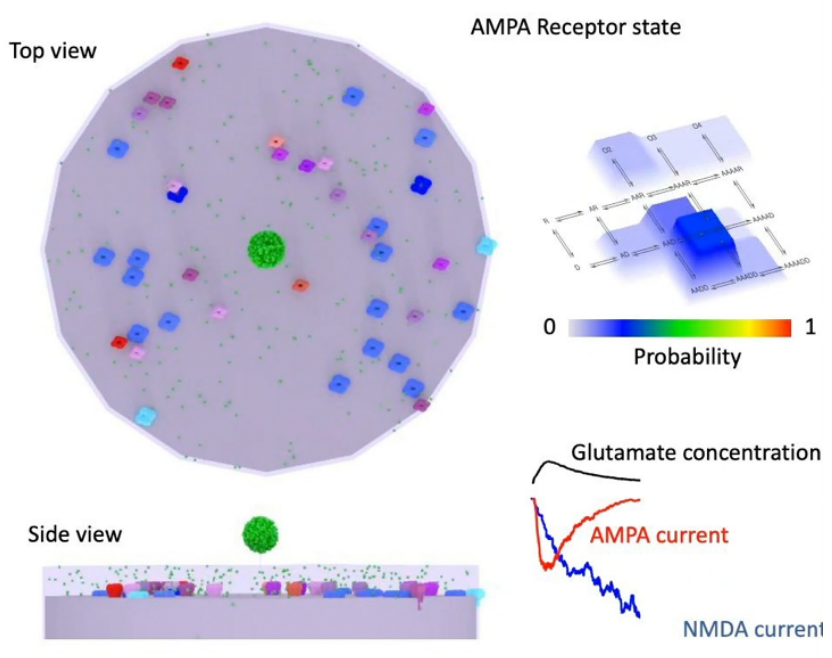

Pore collapse delayed at $0.4 \mathrm{~nm}$

\section{Multimedia video 2: Simulations of full rapid fusion and delayed fusion pore opening.}

Left hand panels - top and side views of vesicle fusing and releasing glutamate into the synaptic cleft. AMPA receptor state probabilities are shown as a color coded lookup in 3D relief. Simulated cleft glutamate concentrations (black), AMPA receptor current (red) and NMDA receptor current (blue) are shown up to the clip time point. Right hand panels show the same but during delayed fusion pore opening. Receptor colors are dependent on state (Fig 7D). The still is of the video $11.19 \mathrm{~ms}$ after the start of fusion. 


\section{References}

Alabi AA, Tsien RW (2013) Perspectives on kiss-and-run: role in exocytosis, endocytosis, and neurotransmission. Annual review of physiology 75:393-422.

Alford S, Grillner S (1991) The involvement of $\mathrm{GABA}_{B}$ receptors and coupled G-proteins in spinal GABAergic presynaptic inhibition. The Journal of Neuroscience 11:3718-3726.

Asztely F, Erdemli G, Kullmann DM (1997) Extrasynaptic glutamate spillover in the hippocampus: dependence on temperature and the role of active glutamate uptake. Neuron 18:281-293.

Balaji J, Ryan TA (2007) Single-vesicle imaging reveals that synaptic vesicle exocytosis and endocytosis are coupled by a single stochastic mode. Proceedings of the National Academy of Sciences of the United States of America 104:20576-20581.

Banke TG, Traynelis SF (2003) Activation of NR1/NR2B NMDA receptors. Nature Neuroscience 6:144152.

Betke KM, Wells CA, Hamm HE (2012) GPCR mediated regulation of synaptic transmission. Progress in neurobiology 96:304-321.

Biederer T, Kaeser PS, Blanpied TA (2017) Transcellular Nanoalignment of Synaptic Function. Neuron 96:680-696.

Blackmer T, Larsen EC, Takahashi M, Martin TF, Alford S, Hamm HE (2001) G protein betagamma subunit-mediated presynaptic inhibition: regulation of exocytotic fusion downstream of $\mathrm{Ca}^{2+}$ entry. Science 292:293-297.

Blackmer T, Larsen EC, Bartleson C, Kowalchyk JA, Yoon E-J, Preininger AM, Alford S, Hamm HE, Martin TFJ (2005) G protein betagamma directly regulates SNARE protein fusion machinery for secretory granule exocytosis. Nature Neuroscience 8:421-425.

Boeijinga PH, Boddeke HW (1993) Serotonergic modulation of neurotransmission in the rat subicular cortex in vitro: a role for 5- $\mathrm{HT}_{1 \mathrm{~B}}$ receptors. Naunyn Schmiedebergs Arch Pharmacol 348:553-557. Boeijinga PH, Boddeke HW (1996) Activation of 5- $\mathrm{HT}_{1 \mathrm{~B}}$ receptors suppresses low but not high frequency synaptic transmission in the rat subicular cortex in vitro. Brain research 721:59-65. 
Bonaventure P, Voorn P, Luyten WH, Jurzak M, Schotte A, Leysen JE (1998) Detailed mapping of serotonin 5-HT1B and 5-HT1D receptor messenger RNA and ligand binding sites in guinea-pig brain and trigeminal ganglion: clues for function. Neuroscience 82:469-484.

Buhot MC, Wolff M, Benhassine N, Costet P, Hen R, Segu L (2003) Spatial learning in the 5-HT1B receptor knockout mouse: selective facilitation/impairment depending on the cognitive demand. Learn Mem 10:466-477.

Chang CW, Chiang CW, Jackson MB (2017) Fusion pores and their control of neurotransmitter and hormone release. J Gen Physiol 149:301-322.

Charlton MP, Smith SJ, Zucker RS (1982) Role of presynaptic calcium ions and channels in synaptic facilitation and depression at the squid giant synapse. J Physiol 323:173-193.

Chen BC et al. (2014) Lattice light-sheet microscopy: Imaging molecules to embryos at high spatiotemporal resolution. Science 346:439-+.

Chen $\mathrm{H}$, Tang AH, Blanpied TA (2018) Subsynaptic spatial organization as a regulator of synaptic strength and plasticity. Curr Opin Neurobiol 51:147-153.

Chen X-K, Wang L-C, Zhou Y, Cai Q, Prakriya M, Duan K-L, Sheng Z-H, Lingle C, Zhou Z (2005) Activation of GPCRs modulates quantal size in chromaffin cells through G(betagamma) and PKC. Nature Neuroscience 8:1160-1168.

Choi S, Klingauf J, Tsien RW (2000) Postfusional regulation of cleft glutamate concentration during LTP at \&apos;silent synapses\&apos;. Nature neuroscience 3:330-336.

Choi S, Klingauf J, Tsien RW (2003) Fusion pore modulation as a presynaptic mechanism contributing to expression of long-term potentiation. Philosophical transactions of the Royal Society of London Series B, Biological sciences 358:695-705.

Christie JM, Jahr CE (2006) Multivesicular release at Schaffer collateral-CA1 hippocampal synapses. J Neurosci 26:210-216.

Clements JD, Lester RA, Tong G, Jahr CE, Westbrook GL (1992) The time course of glutamate in the synaptic cleft. Science 258:1498-1501.

Dale N, Roberts A (1985) Dual-component amino-acid-mediated synaptic potentials: excitatory drive for swimming in Xenopus embryos. The Journal of Physiology 363:35-59. 
Davidson C, Stamford JA (1995) Evidence that 5-hydroxytryptamine release in rat dorsal raphe nucleus is controlled by 5-HT1A, 5-HT1B and 5-HT1D autoreceptors. Br J Pharmacol 114:1107-1109.

Del Castillo J, Katz B (1954) Quantal components of the end-plate potential. The Journal of Physiology 124:560-573.

Dobrunz LE, Stevens CF (1997) Heterogeneity of release probability, facilitation, and depletion at central synapses. Neuron 18:995-1008.

Dutar P, Nicoll RA (1988) Pre- and postsynaptic GABAB receptors in the hippocampus have different pharmacological properties. Neuron 1:585-591.

Elhamdani A, Azizi F, Artalejo CR (2006) Double patch clamp reveals that transient fusion (kiss-and-run) is a major mechanism of secretion in calf adrenal chromaffin cells: high calcium shifts the mechanism from kiss-and-run to complete fusion. The Journal of Neuroscience 26:3030-3036.

Fang Q, Zhao Y, Herbst AD, Kim BN, Lindau M (2015) Positively charged amino acids at the SNAP-25 C terminus determine fusion rates, fusion pore properties, and energetics of tight SNARE complex zippering. The Journal of Neuroscience 35:3230-3239.

Foster KA, Crowley JJ, Regehr WG (2005) The influence of multivesicular release and postsynaptic receptor saturation on transmission at granule cell to Purkinje cell synapses. J Neurosci 25:1165511665.

Gandhi SP, Stevens CF (2003) Three modes of synaptic vesicular recycling revealed by single-vesicle imaging. Nature 423:607-613.

Gerachshenko T, Blackmer T, Yoon E-J, Bartleson C, Hamm HE, Alford S (2005) Gbg acts at the C terminus of SNAP-25 to mediate presynaptic inhibition. Nature Neuroscience 8:597-605.

Gerachshenko T, Schwartz E, Bleckert A, Photowala H, Seymour A, Alford S (2009) Presynaptic G protein-coupled receptors dynamically modify vesicle fusion, synaptic cleft glutamate concentrations and motor behavior. The Journal of Neuroscience 29:10221-10233.

Groffen AJA, Friedrich R, Brian EC, Ashery U, Verhage M (2006) DOC2A and DOC2B are sensors for neuronal activity with unique calcium-dependent and kinetic properties. J Neurochem 97:818-833. 
Haas KT, Compans B, Letellier M, Bartol TM, Grillo-Bosch D, Sejnowski TJ, Sainlos M, Choquet D, Thoumine O, Hosy E (2018) Pre-post synaptic alignment through neuroligin-1 tunes synaptic transmission efficiency. Elife 7:e31755.

Hamid E, Church E, Alford S (2019) Quantitation and Simulation of Single Action Potential-Evoked $\mathrm{Ca}(2+)$ Signals in CA1 Pyramidal Neuron Presynaptic Terminals. eNeuro 6.

Hamid E, Church E, Wells CA, Zurawski Z, Hamm HE, Alford S (2014) Modulation of neurotransmission by GPCRs is dependent upon the microarchitecture of the primed vesicle complex. The Journal of Neuroscience 34:260-274.

Harata NC, Choi S, Pyle JL, Aravanis AM, Tsien RW (2006) Frequency-dependent kinetics and prevalence of kiss-and-run and reuse at hippocampal synapses studied with novel quenching methods. Neuron 49:243-256.

Herron CE, Lester RA, Coan EJ, Collingridge GL (1986) Frequency-dependent involvement of NMDA receptors in the hippocampus: a novel synaptic mechanism. Nature 322:265-268.

Hessler NA, Shirke AM, Malinow R (1993) The probability of transmitter release at a mammalian central synapse. Nature 366:569-572.

Jackman SL, Regehr WG (2017) The Mechanisms and Functions of Synaptic Facilitation. Neuron 94:447464.

Jackman SL, Turecek J, Belinsky JE, Regehr WG (2016) The calcium sensor synaptotagmin 7 is required for synaptic facilitation. Nature 529:88-91.

Kerr RA, Bartol TM, Kaminsky B, Dittrich M, Chang J-CJ, Baden SB, Sejnowski TJ, Stiles JR (2008) Fast monte carlo simulation methods for biological reaction-diffusion systems in solution and on surfaces. SIAM journal on scientific computing : a publication of the Society for Industrial and Applied Mathematics 30:3126.

Lein ES et al. (2007) Genome-wide atlas of gene expression in the adult mouse brain. Nature 445:168176.

Lester RA, Clements JD, Westbrook GL, Jahr CE (1990) Channel kinetics determine the time course of NMDA receptor-mediated synaptic currents. Nature 346:565-567. 
Liao D, Hessler NA, Malinow R (1995) Activation of postsynaptically silent synapses during pairinginduced LTP in CA1 region of hippocampal slice. Nature 375:400-404.

Manz KM, Baxley AG, Zurawski Z, Hamm HE, Grueter BA (2019) Heterosynaptic GABAB Receptor Function within Feedforward Microcircuits Gates Glutamatergic Transmission in the Nucleus Accumbens Core. J Neurosci 39:9277-9293.

Marvin JS, Borghuis BG, Tian L, Cichon J, Harnett MT, Akerboom J, Gordus A, Renninger SL, Chen TW, Bargmann Cl, Orger MB, Schreiter ER, Demb JB, Gan WB, Hires SA, Looger LL (2013) An optimized fluorescent probe for visualizing glutamate neurotransmission. Nat Methods 10:162-170.

Maschi D, Klyachko VA (2020) Spatiotemporal dynamics of multi-vesicular release is determined by heterogeneity of release sites within central synapses. Elife 9.

Mizutani H, Hori T, Takahashi T (2006) 5-HT1B receptor-mediated presynaptic inhibition at the calyx of Held of immature rats. The European journal of neuroscience 24:1946-1954.

Nautiyal KM, Tritschler L, Ahmari SE, David DJ, Gardier AM, Hen R (2016) A Lack of Serotonin 1B Autoreceptors Results in Decreased Anxiety and Depression-Related Behaviors. Neuropsychopharmacology : official publication of the American College of Neuropsychopharmacology 41:2941-2950.

O'Keefe J (1990) A computational theory of the hippocampal cognitive map. Prog Brain Res 83:301-312.

Pang ZP, Bacaj T, Yang X, Zhou P, Xu W, Südhof TC (2011) Doc2 supports spontaneous synaptic transmission by a $\mathrm{Ca}(2+)$-independent mechanism. Neuron 70:244-251.

Pawlu C, DiAntonio A, Heckmann M (2004) Postfusional control of quantal current shape. Neuron 42:607618.

Photowala H, Blackmer T, Schwartz E, Hamm HE, Alford S (2006) G protein betagamma-subunits activated by serotonin mediate presynaptic inhibition by regulating vesicle fusion properties. Proc Natl Acad Sci U S A 103:4281-4286.

Robert A, Howe JR (2003) How AMPA receptor desensitization depends on receptor occupancy. The Journal of Neuroscience 23:847-858.

Rocha BA, Scearce-Levie K, Lucas JJ, Hiroi N, Castanon N, Crabbe JC, Nestler EJ, Hen R (1998) Increased vulnerability to cocaine in mice lacking the serotonin-1B receptor. Nature 393:175-178. 
Rost BR, Nicholson P, Ahnert-Hilger G, Rummel A, Rosenmund C, Breustedt J, Schmitz D (2011)

Activation of metabotropic GABA receptors increases the energy barrier for vesicle fusion. $\mathrm{J}$ Cell

Sci 124:3066-3073.

Rudolph S, Tsai MC, von Gersdorff H, Wadiche JI (2015) The ubiquitous nature of multivesicular release.

Trends Neurosci 38:428-438.

Sari Y (2004) Serotonin1B receptors: from protein to physiological function and behavior. Neuroscience and biobehavioral reviews 28:565-582.

Schwartz EJ, Blackmer T, Gerachshenko T, Alford S (2007) Presynaptic G-protein-coupled receptors regulate synaptic cleft glutamate via transient vesicle fusion. The Journal of Neuroscience 27:5857-5868.

Sigworth FJ (1983) Electronic design of the patch clamp. In: Single-Channel Recording (Sakmann B, Neher E, eds), pp 3-35. New York: Plenum Press.

Silinsky EM (1984) On the mechanism by which adenosine receptor activation inhibits the release of acetylcholine from motor nerve endings. The Journal of Physiology 346:243-256.

Singer JH, Lassova L, Vardi N, Diamond JS (2004) Coordinated multivesicular release at a mammalian ribbon synapse. Nat Neurosci 7:826-833.

Spruce AE, Breckenridge LJ, Lee AK, Almers W (1990) Properties of the fusion pore that forms during exocytosis of a mast cell secretory vesicle. Neuron 4:643-654.

Svenningsson P, Chergui K, Rachleff I, Flajolet M, Zhang X, El Yacoubi M, Vaugeois JM, Nomikos GG, Greengard P (2006) Alterations in 5-HT1B receptor function by 11 in depression-like states. Science (New York, NY) 311:77-80.

Swandulla D, Hans M, Zipser K, Augustine GJ (1991) Role of residual calcium in synaptic depression and posttetanic potentiation: fast and slow calcium signaling in nerve terminals. Neuron 7:915-926.

Takahashi M, Freed R, Blackmer T, Alford S (2001) Calcium influx-independent depression of transmitter release by 5-HT at lamprey spinal cord synapses. The Journal of Physiology 532:323-336.

Tang A-H, Chen H, Li TP, Metzbower SR, MacGillavry HD, Blanpied TA (2016) A trans-synaptic nanocolumn aligns neurotransmitter release to receptors. Nature 536:210-214. 
Tedford HW, Zamponi GW (2006) Direct G protein modulation of Cav2 calcium channels. Pharmacol Rev 58:837-862.

Tiger M, Varnas K, Okubo Y, Lundberg J (2018) The 5-HT1B receptor - a potential target for antidepressant treatment. Psychopharmacology (Berl) 235:1317-1334.

Vardjan N, Jorgacevski J, Zorec R (2013) Fusion pores, SNAREs, and exocytosis. The Neuroscientist : a review journal bringing neurobiology, neurology and psychiatry 19:160-174.

Vardjan N, Stenovec M, Jorgacevski J, Kreft M, Zorec R (2007) Subnanometer fusion pores in spontaneous exocytosis of peptidergic vesicles. The Journal of Neuroscience 27:4737-4746.

Vyleta NP, Smith SM (2011) Spontaneous glutamate release is independent of calcium influx and tonically activated by the calcium-sensing receptor. J Neurosci 31:4593-4606.

Wu LG, Saggau P (1995) GABAB receptor-mediated presynaptic inhibition in guinea-pig hippocampus is caused by reduction of presynaptic Ca2+ influx. The Journal of Physiology 485 ( Pt 3):649-657.

Yoon E-J, Hamm HE, Currie KPM (2008) G protein betagamma subunits modulate the number and nature of exocytotic fusion events in adrenal chromaffin cells independent of calcium entry. Journal of neurophysiology 100:2929-2939.

Yoon E-J, Gerachshenko T, Spiegelberg BD, Alford S, Hamm HE (2007) Gbetagamma interferes with Ca2+-dependent binding of synaptotagmin to the soluble $\mathrm{N}$-ethylmaleimide-sensitive factor attachment protein receptor (SNARE) complex. Molecular pharmacology 72:1210-1219.

Zifa E, Fillion G (1992) 5-Hydroxytryptamine receptors. Pharmacological reviews 44:401-458.

Zurawski Z, Page B, Chicka MC, Brindley RL, Wells CA, Preininger AM, Hyde K, Gilbert JA, CruzRodriguez O, Currie KPM, Chapman ER, Alford S, Hamm HE (2017) Gßy directly modulates vesicle fusion by competing with synaptotagmin for binding to neuronal SNARE proteins embedded in membranes. J Biol Chem 292:12165-12177.

Zurawski Z, Thompson Gray AD, Brady LJ, Page B, Church E, Harris NA, Dohn MR, Yim YY, Hyde K, Mortlock DP, Jones CK, Winder DG, Alford S, Hamm HE (2019) Disabling the GbetagammaSNARE interaction disrupts GPCR-mediated presynaptic inhibition, leading to physiological and behavioral phenotypes. Sci Signal 12. 